\title{
Neural Substrates of Auditory Emotion Recognition Deficits in Schizophrenia
}

\author{
Joshua T. Kantrowitz, ${ }^{1,2}$ Matthew J. Hoptman, ${ }^{1,4}$ David I. Leitman, ${ }^{3}$ Marta Moreno-Ortega, ${ }^{2}$ Jonathan M. Lehrfeld, ${ }^{1}$ \\ Elisa Dias, ${ }^{1,4}$ Pejman Sehatpour, ${ }^{1,2}$ Petri Laukka, ${ }^{5}$ Gail Silipo, ${ }^{1}$ and Daniel C. Javitt ${ }^{1,2}$ \\ ${ }^{1}$ Schizophrenia Research Center, Nathan Kline Institute, Orangeburg, New York 10962, ${ }^{2}$ Psychiatry, Columbia University College of Physicians and \\ Surgeons, New York, New York 10032, ${ }^{3}$ Psychiatry-Neuropsychiatry Section, University of Pennsylvania, Philadelphia, Pennsylvania 19104, ${ }^{4}$ Psychiatry, \\ New York University, New York, New York 10016, and ${ }^{5}$ Psychology, Stockholm University, Stockholm, Sweden
}

Deficits in auditory emotion recognition (AER) are a core feature of schizophrenia and a key component of social cognitive impairment. AER deficits are tied behaviorally to impaired ability to interpret tonal ("prosodic") features of speech that normally convey emotion, such as modulations in base pitch (F0M) and pitch variability (F0SD). These modulations can be recreated using synthetic frequency modulated (FM) tones that mimic the prosodic contours of specific emotional stimuli. The present study investigates neural mechanisms underlying impaired AER using a combined event-related potential/resting-state functional connectivity (rsfMRI) approach in 84 schizophrenia/schizoaffective disorder patients and 66 healthy comparison subjects. Mismatch negativity (MMN) to FM tones was assessed in 43 patients/36 controls. rsfMRI between auditory cortex and medial temporal (insula) regions was assessed in 55 patients/51 controls. The relationship between AER, MMN to FM tones, and rsfMRI was assessed in the subset who performed all assessments (14 patients, 21 controls). As predicted, patients showed robust reductions in MMN across FM stimulus type ( $p=0.005)$, particularly to modulations in F0M, along with impairments in AER and FM tone discrimination. MMN source analysis indicated dipoles in both auditory cortex and anterior insula, whereas rsfMRI analyses showed reduced auditory-insula connectivity. MMN to FM tones and functional connectivity together accounted for $\sim 50 \%$ of the variance in AER performance across individuals. These findings demonstrate that impaired preattentive processing of tonal information and reduced auditory-insula connectivity are critical determinants of social cognitive dysfunction in schizophrenia, and thus represent key targets for future research and clinical intervention.

Key words: affective prosody; ERP; mismatch negativity; resting-state MRI; schizophrenia; social cognition

Significance Statement

Schizophrenia patients show deficits in the ability to infer emotion based upon tone of voice [auditory emotion recognition (AER)] that drive impairments in social cognition and global functional outcome. This study evaluated neural substrates of impaired AER in schizophrenia using a combined event-related potential/resting-state fMRI approach. Patients showed impaired mismatch negativity response to emotionally relevant frequency modulated tones along with impaired functional connectivity between auditory and medial temporal (anterior insula) cortex. These deficits contributed in parallel to impaired AER and accounted for $\sim 50 \%$ of variance in AER performance. Overall, these findings demonstrate the importance of both auditory-level dysfunction and impaired auditory/insula connectivity in the pathophysiology of social cognitive dysfunction in schizophrenia.

\section{Introduction}

Although auditory processing was once considered an "intact simple function" in schizophrenia (Bleuler, 1950), deficits in

Received Nov. 5, 2014; revised Sept. 28, 2015; accepted 0ct. 3, 2015.

Author contributions: J.T.K., D.I.L., E.D., P.L., and D.C.J. designed research; J.T.K., M.J.H., D.I.L., J.M.L., and G.S. performed research; P.L. contributed unpublished reagents/analytic tools; J.T.K., M.J.H., M.M.-O., J.M.L., E.D., P.S., G.S., and D.C.J. analyzed data; J.T.K., M.J.H., and D.C.J. wrote the paper.

This work was supported in part by the National Center for Research Resources and the National Center for Advancing Translational Sciences, National Institutes of Health Grant UL1 RR024156, and the Dr. Joseph E. and Lillian Pisetsky Young Investigator Award for Clinical Research in Serious Mental IIIness to J.T.K., Grants R01 DA03383, P50 MH086385, and R37 MH49334 to D.C.J., Grants R21 MH084031, R01 MH064783, and R01 MH084848 to M.J.H., Grant early sensory processing of auditory information have been increasingly documented over recent years by multiple independent groups (Leitman et al., 2007; Javitt, 2009; Pinheiro et al., 2013; Kantrowitz et al., 2014b). In particular, deficits in auditory emotion recognition (AER) contribute disproportionately to im-

K01MH094689, and a National Alliance for Research on Schizophrenia and Depression (Brain and Behavior Research Foundation) Young Investigator to D.I.L. The content is solely the responsibility of the authors and does not necessarily represent the official views of the National Institutes of Health.

J.T.K. reports having received consulting payments within the last 36 months from Otsuka Pharmaceuticals, Vindico Medical Education, Annenberg Center for Health Sciences at Eisenhower, Health Advances, LLC, Strategic Edge Communications, Havas Life, and Cowen and Company. He has conducted clinical research supported by the 
paired global outcome (Green et al., 2000; Edwards et al., 2001) and correlate with impairments in higher-level function. For example, reduced ability to discriminate simple tones correlates with impairments in emotion recognition (Gold et al., 2012), theory of mind (Kantrowitz et al., 2014a), and reading ability (Revheim et al., 2014) in schizophrenia patients.

Although the neural substrates of AER impairments are incompletely understood, studies have implicated regions, including auditory cortex, inferior frontal gyrus, and medial temporal structures (e.g., anterior insula, amygdala) in normal AER processing (Wildgruber et al., 2006; Leitman et al., 2011b; Bestelmeyer et al., 2014). This study uses complementary eventrelated potential (ERP) and resting-state functional connectivity (rsfMRI) measures to evaluate neural mechanisms underlying AER impairments in schizophrenia.

In speech, emotional information ("affective prosody") is conveyed largely by tone of voice. For example, happy utterances typically have high base pitch (FOM) and pitch variability (FOSD), whereas sad utterances are characterized by lower FOM and FOSD (Banse and Scherer, 1996; Juslin and Laukka, 2001). Overall speech volume (intensity) and presence of high-frequency noise (HF500) contribute to perception of anger and fear (Whiteside, 1999). These features can be modeled by synthetic, frequency modulated (FM) tones that mimic tonal parameters associated with specific types of utterances (Kantrowitz et al., 2013).

Schizophrenia patients show impaired sensitivity to changes in pitch and duration (Todd et al., 2003; Gold et al., 2012), processes that are known to localize to primary auditory cortex (Tramo et al., 2002), along with deficits in sensitivity to modulation of intensity discrimination (Bach et al., 2011). For AER, we have previously demonstrated relatively greater deficit in ability to use pitch-based (F0M, FOSD) versus absolute intensity-based (intensity, HF500) features of speech (Leitman et al., 2010; Gold et al., 2012).

The neural mechanisms underlying FM tone processing can be evaluated using mismatch negativity (MMN) (Leitman et al., 2011a), an ERP component that reflects preattentive auditory processing within superficial layers of auditory cortex (Javitt et al., 1994; Tiitinen et al., 1994; Javitt and Sweet, 2015). Deficits in MMN generation to deviations in simple auditory features, such as pitch, duration, or intensity, have been extensively replicated in schizophrenia (Garrido et al., 2009; Friedman et al., 2012; Light et al., 2012) and tied to NMDAR dysfunction in both monkey (Javitt et al., 1996; Gil-da-Costa et al., 2013) and human (Umbricht et al., 2000; Heekeren et al., 2008; Javitt et al., 2011; Gunduz-Bruce et al., 2012) investigations. This is the first study to investigate $\mathrm{MMN}$ to emotionally relevant FM tones relative to AER deficits in schizophrenia.

To complement ERP, we used rsfMRI to interrogate functional connectivity between auditory and medial temporal structures. In healthy volunteers, we observed bitemporal MMN responses to FM deviant tones suggesting potential activation of

National Institute of Mental Health, the Stanley Foundation, Roche-Genetech, Forum, Psychogenics, Sunovion, Novartis, Pfizer Lilly, and GlaxoSmithKline. He owns a small number of shares of common stock in GlaxoSmithKline. D.C.J. reports having received consulting payments within the last 2 years from Sunovion, Forum, and Takeda. He has received research support from Roche. He holds intellectual property rights for use of NMDA modulators in treatment of neuropsychiatric disorders. He holds equity in Glytech, AASI, and NeuroRx, and serves on the advisory board of Promentis and NeuroRx. The remaining authors declare no competing financial interests.

Correspondence should be addressed to either Dr. Joshua T. Kantrowitz or Dr. Daniel C. Javitt, Nathan Kline Institute for Psychiatric Research, 140 Old Orangeburg Road, Orangeburg, NY 10962, E-mail: jkantrowitz@nki.rfmh.org or javitt@nki.rfmh.org.

DOI:10.1523/JNEUROSCI.4603-14.2015

Copyright $\odot 2015$ the authors $\quad 0270-6474 / 15 / 3514910-13 \$ 15.00 / 0$
Table 1. Study demographics ${ }^{a}$

\begin{tabular}{lll}
\hline & Control $(n=66)$ & Patient $(n=84)$ \\
\hline Age & $38.2 \pm 10.9$ & $39.4 \pm 10.6$ \\
Male (\%) & 71 & 81 \\
Socioeconomic status, parental* & $42.7 \pm 14.5$ & $36.0 \pm 12.0$ \\
Socioeconomic status, participant* & $44.0 \pm 10.8$ & $27.6 \pm 15.1$ \\
Chlorpromazine equivalents (Woods 2003) & - & $932 \pm 1032 \mathrm{mg}$ \\
Atypical (alone or combination) (\%) & - & $90 \%$ \\
Illness duration & - & $15.9 \pm 9.4$ \\
PANSS total & - & $73.2 \pm 14.9$ \\
PANSS positive & - & $19.1 \pm 6.2$ \\
PANSS negative & - & $18.1 \pm 4.7$ \\
PANSS general & - & $36.0 \pm 7.7$ \\
MMN to FM tones (n) & 36 & 43 \\
MRI $(n)^{b}$ & 51 & 55 \\
Both MRI and MMN to FM tones $(n)$ & 21 & 14 \\
MMN to non-FM (simple) tones $(n)$ & 23 & 28 \\
\hline
\end{tabular}

a Parental socioeconomic status information was not available for 27 patients and 8 controls. Individual SES data were unavailable for 9 patients and one control. Chlorpromazine equivalents was unavailable for 3 patients. PANSS was unavailable on 21. Antipsychotic subtype was unavailable on 4 patients. PANSS, Positive and negative syndrome scale for schizophrenia.

${ }^{b} \mathrm{~A}$ total of $63 \%$ of controls and $63 \%$ of patients were scanned on the $3 \mathrm{~T}$, with the remainder on $1.5 \mathrm{~T}$.

*Significant difference on independent sample $t$ test.

both medial temporal and auditory structures (Leitman et al., 2011a). In addition, functional dysconnectivity has been shown to contribute to cognitive dysfunction in schizophrenia, across frontal, limbic, and parietal networks (Deserno et al., 2012; Mukherjee et al., 2012; Hoptman et al., 2014). In the present report, rsfMRI "seeds" were placed in bilateral auditory and anterior insula cortex based on MMN source localization, and contributions of sensory-insular dysconnectivity to impaired AER function were assessed.

We hypothesized that (1) MMN generation to emotionally relevant FM features and (2) auditory-insular connectivity would be significantly reduced in schizophrenia and that these deficits would contribute in parallel to AER impairments, reflecting combined effects of auditory dysfunction and sensory-insular dysconnectivity. This is the first study of which we are aware to use combined ERP/rsfMRI analyses to assess neural substrates underlying social cognitive impairment in schizophrenia.

\section{Materials and Methods}

Subjects. All subjects signed informed consent as approved by the Nathan Kline Institute (NKI) Institutional Review Board. Subjects consisted of 84 medicated patients ( 68 males and 16 females) recruited from NKI and 66 controls (47 males and 19 females) and consisted of all available subjects who participated in the EEG recording and/or rsfMRI. A subset of subjects (14 patients and 21 controls) completed both MMN and rsfMRI (Table 1). All subjects were interviewed with the Structured Clinical Interview for DSM-IV (First et al., 1996). Patients met criteria for either schizophrenia or schizoaffective disorder, whereas controls had no history of a major Axis I disorder. Subjects were excluded if any neurological/sensory disorders were noted on medical history, or for substance dependence (within 6 months) and/or abuse (1 month). Data are mean \pm SD.

Behavioral tasks and symptom ratings, including the Positive and Negative Symptom Scale (Kay et al., 1987), were obtained from a subsample of patients (Table 1).

MMN to FM tones. ERPs were obtained to synthetic FM tones that differed in pitch, intensity, or HF500. As previously described (Kantrowitz et al., 2013), the FM tones were developed by measurement of acoustic cues of the Juslin and Laukka's (Juslin and Laukka, 2001) prosody stimulus set using PRAAT software. FM tones were synthesized (Adobe Audition) to be $500 \mathrm{~ms}$ in length with a modulation frequency of $3 \mathrm{~Hz}(1.5$ cycles per tone), at a nominal intensity of $75 \mathrm{~dB}$ sound pressure level. The 

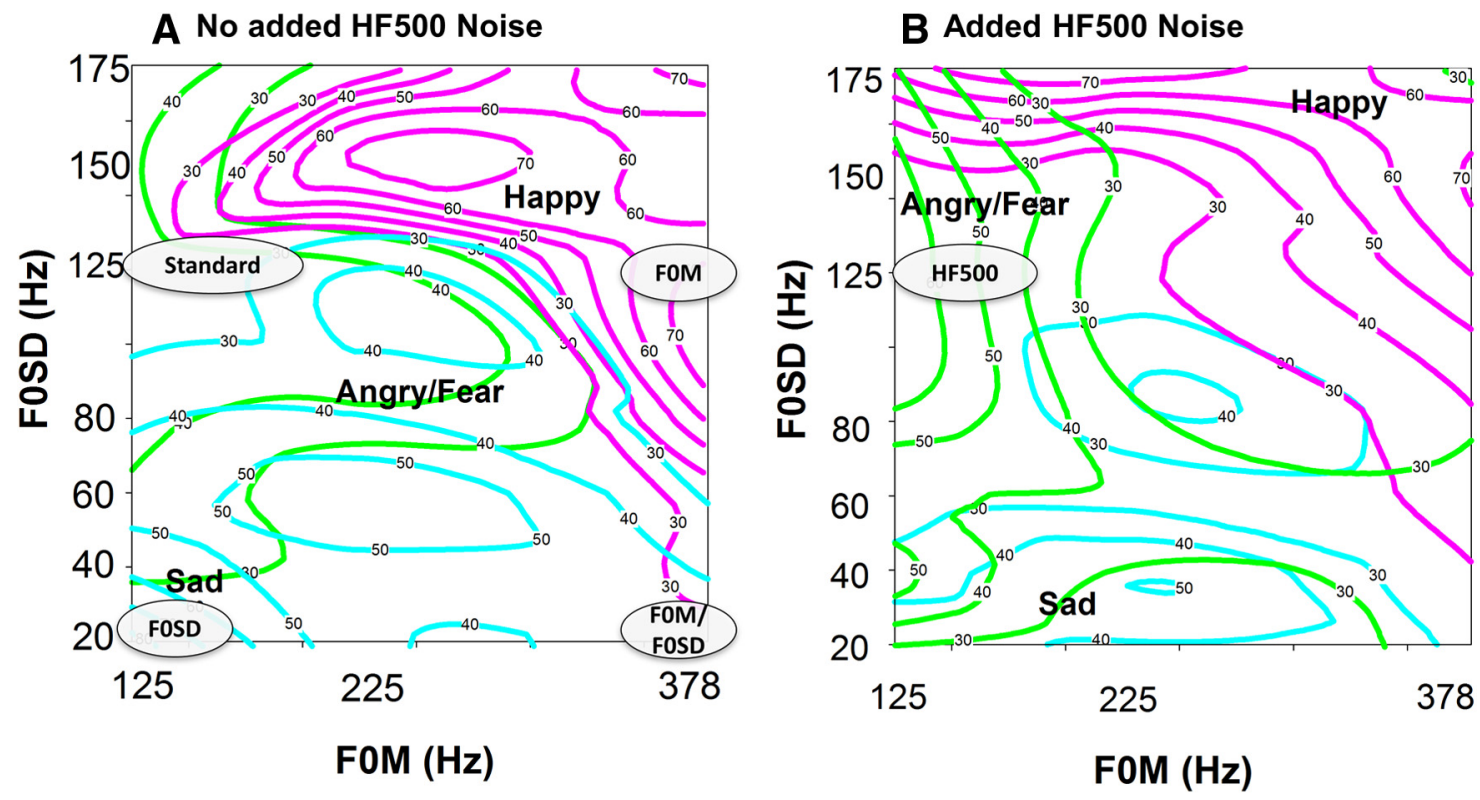

Figure 1. Schematic diagram of stimulus properties for standard and indicated deviant stimuli, relative to a contour plot of identification patterns for FM tones varied across changes in FoM $(x$-axis) and FOSD ( $y$-axis) without ( $\boldsymbol{A}$ ) and with (B) added HF500. Contour plots are from controls and have been reported previously (Kantrowitz et al., 2013). Gray ovals represent location of tested FM tones. Numbers on the colored lines indicate the percentage response associated with that area. Pink represents happy; cyan represents sad; green represents angry/fear.

"standard" tone had moderate levels of F0M and F0SD (e.g., an F0M/ F0SD of $125 / 125 \mathrm{~Hz}$ ) and was designed to be emotionally ambiguous, whereas the deviants were designed to mimic specific emotions (Fig. 1). HF500 was added as regularly distributed noise.

The six deviants were modified from the standard tone as follows (Fig. 1): (1) F0M: increased base pitch with unchanged pitch variability (i.e., $378 \mathrm{~Hz} / 125 \mathrm{~Hz}$ ); typically perceived as happy; (2) F0SD: unchanged base pitch with decreased pitch variability (i.e., $125 \mathrm{~Hz} / 20 \mathrm{~Hz}$ ); typically perceived as sad; (3) HF500: adding an overlay of HF500 noise with unchanged pitch characteristics; typically perceived as angry or fearful; (4) intensity: increasing the intensity (volume) to $85 \mathrm{~dB}$ with unchanged pitch characteristics; typically perceived as angry or fearful; (5) dual (F0M/F0SD): varying both base pitch and variability $(378 \mathrm{~Hz} / 20 \mathrm{~Hz})$; leads to a stimulus that differs physically from the standard but does not convey a predominant emotion percept; and (6) non-FM: a simple, non-FM modulated tone $(125 \mathrm{~Hz})$, which is perceived primarily as neutral or no emotion.

Stimuli were presented through headphones with an interstimulus interval of $250 \mathrm{~ms}$. During MMN testing, subjects were not informed of the emotional intent, and watched a silent, unrelated movie. A multidimensional, "optimized" design (Näätänen et al., 2004) was used, allowing for multiple deviants to be assessed simultaneously (Fig. 2). Four 950 tone blocks were used, with each block divided into an "oddball" section (Fig. 2A), followed immediately by a "repetitive N1" section (Fig. 2B). In the oddball section, 600 tones were presented: standard tones ( 300 total/ $50 \%$ ) alternated with one of the six deviants (50 of each deviant tone per block $\sim 8.33 \%$ for each deviant). The deviant tone could not be the same as one of the previous four deviants. In the repetitive N1 section, 50 repeats of each of the seven tones (350 total tones, 50 each) were presented. Thus, each tone was presented both as a deviant against a background of the more frequent, emotionally ambiguous "standard" stimuli in the oddball section and repetitively in the "repetitive N1" section.

Subsequently, the tones were played again in the FM tone task, as previously presented (Kantrowitz et al., 2013). One patient did not participate in this portion of the experiment. Subjects were asked to identify the emotional percept corresponding to each tone (happy, sad, anger, fear, or neutral). Non-FM and intensity stimuli were not tested in this task but were preferentially identified as neutral (54\%) and angry (66\%), respectively, in a separate pilot experiment.

EEG recordings. EEG data were obtained from 72 scalp electrodes using either a Biosemi or Advanced Neurotechnology digital recording system with previously reported methods (Friedman et al., 2012) and were stored along with digital timing tags for subsequent offline analysis. No significant differences in response pattern were observed between the systems.

Epochs ( -100 to $250 \mathrm{~ms}$ ) were created offline and low-pass filtered at $45 \mathrm{~Hz}$ ( $48 \mathrm{db}$ down), and artifact rejected at $\pm 120 \mu \mathrm{V}$. Epochs were then averaged offline for each subject and stimulus type. Similar numbers of sweeps were included in patient and control averages across deviants $\left(\right.$ mean $\left.=176.6 \pm 40.6, F_{(1,77)}=0.002, p=0.96\right)$. Similar to previous studies (Sinkkonen and Tervaniemi, 2000; Friedman et al., 2012), averages were then bandpass filtered from $1 \mathrm{~Hz}$ (6 $\mathrm{dB}$ down) to $15 \mathrm{~Hz}$ (24 dB down), referenced to average mastoids and baseline corrected.

MMN to FM tone analysis. Because the morphology of the sensory response to the different stimuli varied with stimulus feature, MMN waveforms were assessed as the difference wave of the response to the same stimulus presented in the oddball section versus in the repetitive $\mathrm{N} 1$ section ("like from like" comparison; Fig. 2C). MMN was calculated as mean amplitude within the selected latency range. Peak amplitude was used to confirm latency window selection. To avoid "circular analysis" ("double-dipping") bias, we followed published guidelines (Kriegeskorte et al., 2009). First, the general analysis plan was based upon a prior methods-only study, which established the basic phenomenon (i.e., MMN to FM deviants) and demonstrated differential latency ranges for features that were apparent at stimulus onset (e.g., F0M) versus features that needed to be extracted from ongoing stimulation (e.g., F0SD) (Leitman et al., 2011a).

Second, to ensure that electrodes that show the cleanest "signal" are used for analysis and are independent of patient/control differences, MMN was analyzed with electrodes selected based upon areas of magnitude of signal-to-noise ratio (across group effect size) for each deviant type based upon the 10/10 recording montage (Le et al., 1998). Third, adjustments to the windows chosen for electrophysiological analysis were based upon the magnitude of response in the two groups ("A + B"), rather than the difference ("A - B"), which produces contrast vectors that are orthogonal (Kriegeskorte et al., 2009).

Unequal numbers of subjects in the two study groups might also influence the results but were not a significant issue ( 43 patients, 36 controls) in the present report. Finally, in the electrophysiology studies, between-group differences were apparent even in distributed source analyses in which all surface data were taken into account. 


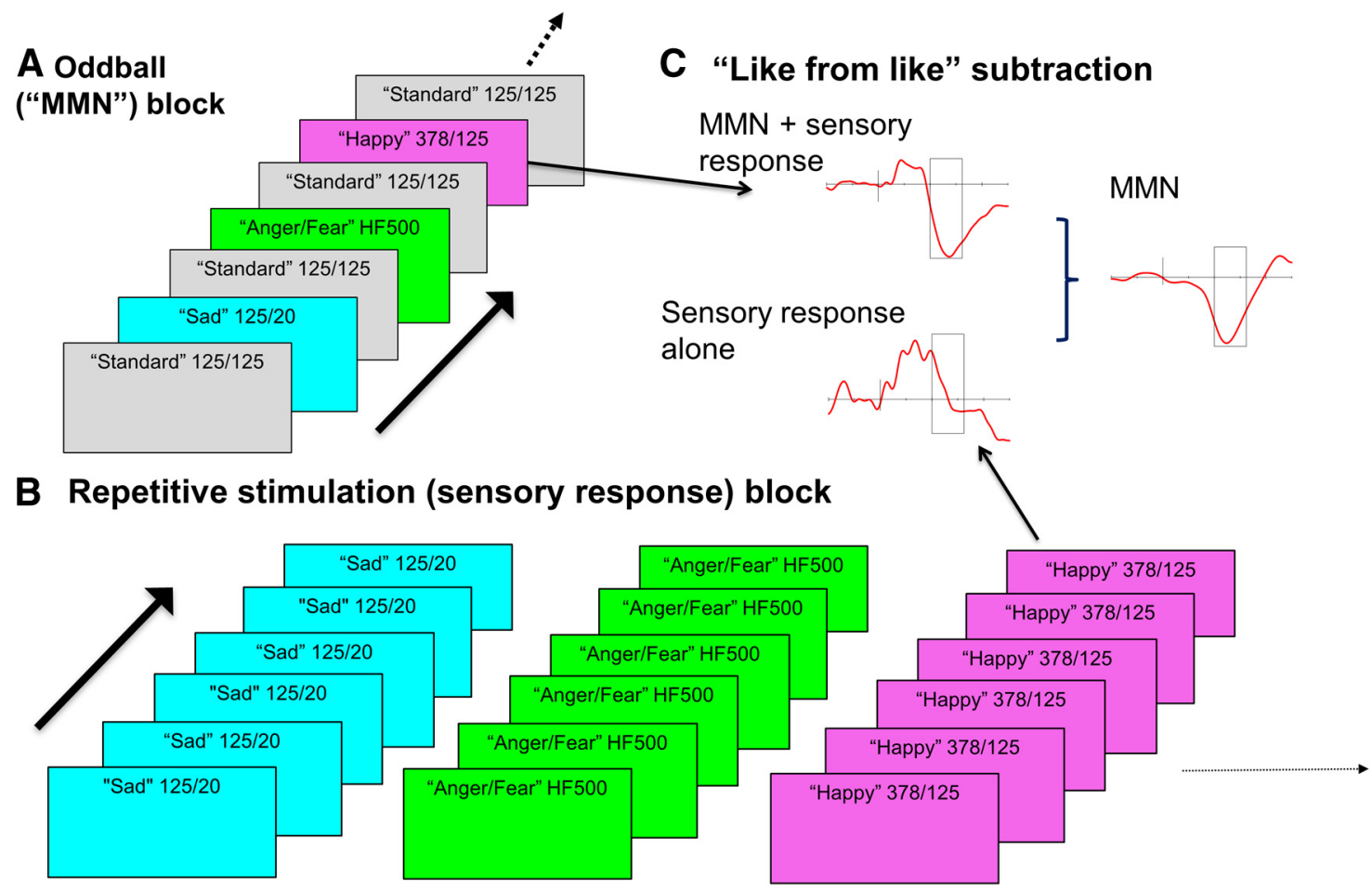

Figure 2. Illustration of MMN to FM tones paradigm. $A$, In the oddball section, 600 tones were presented: standard tones ( 300 total/ $50 \%)$ alternated with 1 of the 6 deviants ( 50 of each deviant tone per block $\sim 8.33 \%$ for each deviant). $\boldsymbol{B}$, In the repetitive $\mathrm{N} 1$ section, 50 repeats of each of the 7 tonal deviants ( 350 total tones, 50 each) were presented. $\boldsymbol{C}$, MMN waveforms were assessed as the difference wave of the response to the same stimulus presented in the oddball block versus in the repetitive stimulation block ("like from like") comparison.

Electrode selection. As in previous studies (Bishop et al., 2005; Leitman et al., 2011a), MMN was analyzed with electrodes selected based upon areas of magnitude of signal-to-noise ratio across group effect size for each deviant type based upon the 10/10 recording montage (Le et al., 1998), as follows: F0M: left, C1, C3, C5, CP1, CP3, FC1, FC3, P3; right, C2, C4, C6, CP2, CP4, FC2, FC4, P4; F0SD: left, AF3, F3, FC1, FC3, C1, C3; right, AF4, F2, F4, FC2, FC4, C2, C4; intensity: left, AF3, F1, F5, FC1, FC3, C3; right, AF4, F2, F6, FC2, FC4, C4; F0M/ F0SD: left, AF3, F1, F3, F5, FC1, C5; right, AF4, F2, F4, F6, FC2, C6; and HF500: left, F3, F5, F7, FC5; right, F4, F6, F8, FC6.

Latency window selection. As observed in our pilot study (Leitman et al., 2011a), N1/MMN latencies to FM tones are prolonged relative to simple, non-FM tones, sometimes peaking up to $200 \mathrm{~ms}$ after stimulus onset. This is presumably due to longer onset times to peak amplitude. In particular, MMN to FOSD is prolonged relative to FOM, likely because F0M (i.e., base pitch) is apparent at stimulus onset, whereas F0SD (i.e., pitch variability) does not become apparent until sufficient "sampling" has occurred to allow the brain to extract variability information. Similar findings of a delayed MMN to FOSD stimuli have been independently reported (Bishop et al., 2005), finding latencies in the 150-300 ms range for F0SD deviant stimuli.

Thus, following the procedures we established in our methodological pilot study (Leitman et al., 2011a), separate ranges were used for analysis, including an "early" window for F0M-, F0M/F0SD-, and HF500-based deviants (100-160 ms) versus a "late" window for F0SD and intensity deviants $(160-250 \mathrm{~ms})$. Our analyzed latency windows differed slightly from our methodological pilot, [(early: 100-160 ms vs $110-185 \mathrm{~ms}$ ) and late (early: $160-250 \mathrm{~ms}$ vs $150-225 \mathrm{~ms}$ )] due to the expanded, novel deviant set (e.g., HF500, intensity) and an earlier peak across group for F0M $(\sim 130 \mathrm{~ms}$ vs $\sim 160 \mathrm{~ms})$. The early window included \pm 1 SD around the across group mean peak, and late window was shifted to cover the remainder of the epoch.

N1 analysis. To assess for registration of auditory stimuli within cortex (Näätänen and Picton, 1987), N1 peak amplitudes in the FCz channel to tones presented in the repetitive N1 section (Fig. $2 B$ ) were analyzed within the 50-200 latency range.
MMN to FM tone source localization. MMN source localization was determined with local auto-regressive average (LAURA) analysis (Michel et al., 2004; Sehatpour et al., 2006; Murray et al., 2008) and BESA 5.3. First, dipole coordinates were derived from the LAURA solution (Figs. $3 D, 4 B)$, yielding bilateral auditory cortex [Talairach coordinates $(X, Y, Z)= \pm 59,-28,8$, planum temporale] and medial temporal (anterior insula) $( \pm 35,5,3)$ dipoles. Subsequent to this, a standard leastsquare dipole fit was made using BESA 5.3. Source waveforms were generated in BESA 5.3 for each subject using these four bilateral dipoles, as well as bilateral eye dipoles $( \pm 28,71,4)$ to control for residual variance generated by blinks/eye movements. For BESA analysis, dipole location was fixed, but orientation was not.

Behavioral tasks: AER and tone matching task. AER was assessed using the abbreviated Juslin and Laukka's (Juslin and Laukka, 2001) emotional prosody task, as described previously (Gold et al., 2012). The stimuli were scored based on the speaker's intended emotion (happy, sad, angry, fear, or neutral). The sentences were semantically neutral (i.e., "It is 11 o'clock"). Correct percentage responses were analyzed across groups, with separate factors extracted for pitch- versus intensity-based AER.

Pitch processing was assessed using a simple (non-FM tone) matching task (Leitman et al., 2010; Petkova et al., 2014). This task consists of pairs of $100 \mathrm{~ms}$ tones in series, with $500 \mathrm{~ms}$ intertone interval. Within each pair, tones are either identical or differed in frequency by specified amounts $(\Delta \mathrm{f})$ in each block $(2.5 \%, 5 \%, 10 \%, 20 \%$, or $50 \%)$. Tones are derived from three reference frequencies $(500,1000$, and $2000 \mathrm{~Hz})$ to avoid learning effects.

MMN to non-FM tone. A subset of subjects (Table 1) also underwent an MMN paradigm, including simple, non-FM stimuli (a standard and duration, intensity, and frequency deviants), as previously reported (Friedman et al., 2012). These measures were used to assess the specificity of the relationship between rsfMRI, MMN to FM tones, and AER and were analyzed as previously reported (Friedman et al., 2012).

rsfMRI methods: MRI acquisition. Scanning took place on the Siemens 3T TiM Trio or $1.5 \mathrm{~T}$ Vision Scanner at the NKI Center for Advanced Brain Imaging. For 3T, subjects ( $n=34$ patients and 32 controls) received an MP-RAGE $(\mathrm{TR}=2500 \mathrm{~ms}$, TE $=3.5 \mathrm{~ms}$, TI $=1200 \mathrm{~ms}$, 
A
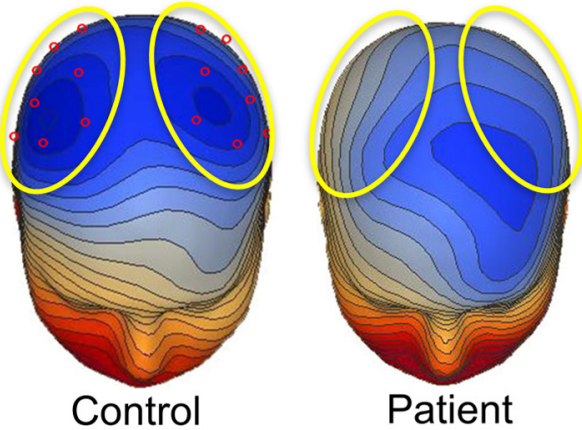

C

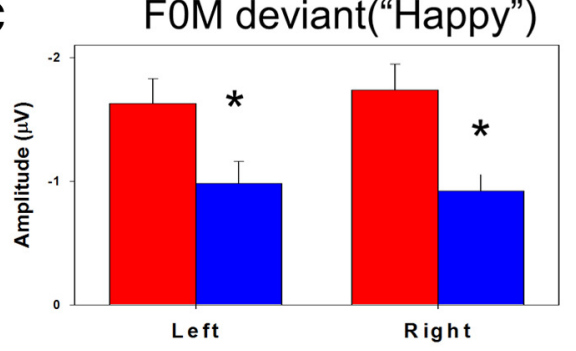

B
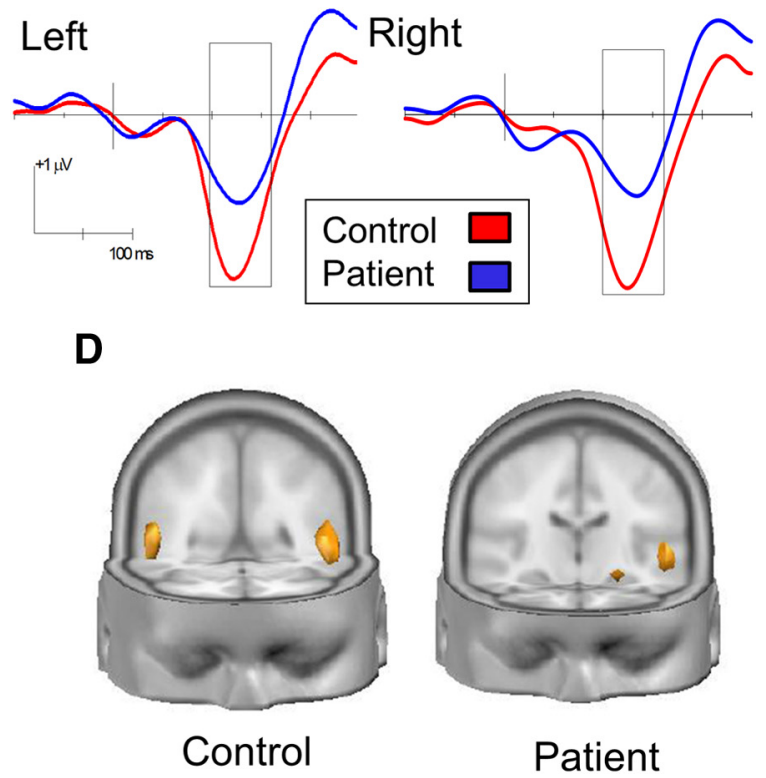

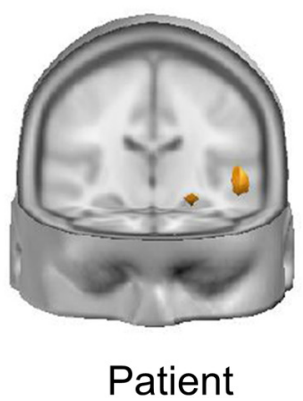

Figure 3. A, Voltage topography maps ( $130 \mathrm{~ms}, 0.10 \mu \mathrm{V} / \mathrm{step})$. Yellow ovals represent electrodes (red) used for statistical analysis. Box represents analyzed latency window (100 - $160 \mathrm{~ms})$. $\boldsymbol{B}$, Grand average MMN waveforms for patients (blue) and controls (red) showing MMN_FOM ("Happy"). C, Mean amplitude over 100-160 ms latency window (D): source localization generated in LAURA. Both groups are shown at the same current density $\left(472 \mu \mathrm{A} / \mathrm{mm}^{3}\right)$. Blue represents patients; red represents controls. ${ }^{*} p<0.05$ patients versus controls.

matrix $=256 \times 256$, FOV $=256$, slice thickness $=1 \mathrm{~mm}, 192$ slices, no gap, 1 acquisition), and a 5 to 6 min resting-state scan $(\mathrm{TR}=2000 \mathrm{~ms}$, $\mathrm{TE}=30 \mathrm{~ms}$, matrix $=96 \times 96, \mathrm{FOV}=240 \mathrm{~mm}, 2.8 \mathrm{~mm}$ slice thickness, 34 slices, $0.5 \mathrm{~mm}$ gap, 180 acquisitions, IPAT $=2$ ). For $1.5 \mathrm{~T}$, participants $(n=21$ patients and 19 controls) received an MP-RAGE T1-weighted scan $(\mathrm{TR}=11.6 \mathrm{~ms}, \mathrm{TE}=4.9 \mathrm{~ms}, \mathrm{TI}=1122 \mathrm{~ms}$, matrix $=256 \times 256$, $\mathrm{FOV}=256 \mathrm{~mm}$, slice thickness $=1 \mathrm{~mm}, 190$ slices, no gap, 1 acquisition), and a $6 \mathrm{~min}$ resting-state $\mathrm{fMRI} \mathrm{scan} \mathrm{(TR}=2000 \mathrm{~ms}, \mathrm{TE}=50 \mathrm{~ms}$, matrix $=64 \times 64, \mathrm{FOV}=224 \mathrm{~mm}, 5 \mathrm{~mm}$ slice thickness, 22 slices, no gap, 180 acquisitions). For the resting-state scan, participants were instructed to close their eyes and remain awake. Research study staff confirmed that subjects remained awake after each scan.

rsfMRI data analysis. Resting-state data were preprocessed as described previously in detail (Hoptman et al., 2014), using Data Processing Assistant for Resting-State fMRI-Advanced (Chao-Gan and Yu-Feng, 2010), which runs under Statistical Parametric Mapping version 8 . Briefly, the first 5 volumes were discarded to eliminate T1 relaxation effects, and time series were truncated to a maximum length of 145 scans. Motion correction was then performed. Functional images were then registered to a standard space echo planar template that comes with Statistical Parametric Mapping distribution, and tissue-type segmentations were derived from anatomical "prior" images in standard space. Nuisance regressors were then removed (Yan et al., 2013a), including motion parameters and their derivatives, global, white matter, CSF time series, and linear and quadratic trends. Data were smoothed with a $6 \mathrm{~mm}$ Gaussian kernel and filtered $(0.1-0.01 \mathrm{~Hz})$. Because small movements from volume to volume can influence rsfMRI results (Power et al., 2012), we computed framewise displacement (FD) for our data (Jenkinson et al., 2002). Participants whose FD values were $>2$ SDs above the overall mean ( 2 controls, 2 patients) were dropped from analyses (Yan et al., $2013 b$ ), yielding the final sample of 51 controls and 55 patients (Table 1 ). The final sample did not differ in $\mathrm{FD}\left(t_{(104)}=1.5, p=0.12\right)$.

Bilateral ROIs in the planum temporale and anterior insula cortex were derived from the source analysis dipoles ( $4 \mathrm{~mm}$ radius spheres). As the source-derived anterior insula regions were adjacent to the amygdala, bilateral ROIs were created for the amygdala as well. The amygdala ROIs were derived from the Harvard-Oxford Structural atlas that is part of FSL, thresholded at $25 \%$. Thus, we extracted rsfMRI between the anterior insula dipole and the portion of the group difference region that contained the anatomical auditory cortex, as derived from the Harvard-Oxford Structural atlas that is part of FSL, thresholded at $25 \%$ probability. This region contained the auditory cortex dipole derived from source analysis of MMN data.

These were then used to extract time series for the relevant ROIs from the residualized images described above. The time series for each insula ROI was correlated with the time series for each primary auditory cortex and amygdala ROI in pairwise fashion within hemisphere. We also conducted voxelwise GLM analyses for the insula source-based ROIs, controlling for magnet (1.5T or 3T) and FD. Group difference contrasts were computed in this analysis. The GLM analyses produced thresholded $z$-statistic maps of clusters defined as a $Z$ threshold of 2.3 and a corrected cluster threshold of $p=0.05$ using Gaussian Random Field theory.

Voxel-based morphometry. Anatomical data were processed with whole-brain voxel-based morphometry (Ashburner and Friston, 2000), implemented in SPM12 software (http://www.fil.ion.ucl.ac.uk/spm) with MATLAB (version 7.90, The MathWorks) on MAC X version 10.9.5 OS. Three-dimensional T1-weighted images were segmented into the three main tissue classes [gray matter (GM), white matter (WM), and $\mathrm{CSF}$ ] with the SPM unified segmentation algorithm (Ashburner and Friston, 2005). The GM and WM images were next spatially normalized to a group-specific template and then to MNI space with a diffeomorphic image registration tool kit (Diffeomorphic Anatomical Registration using Exponentiated Lie algebra) in $1.5 \mathrm{~mm}$ cubic resolution (Ashburner, 2007). The images were modulated with the individual Jacobian determinants to preserve the local amount of GM and WM. Modulation was achieved by multiplying voxel values in the segmented images by the Jacobian determinants derived from the spatial normalization step. In effect, the analysis of modulated data tests for regional differences in the absolute amount of GM. Finally, images were smoothed with an $8 \mathrm{~mm}$ FWHM isotropic Gaussian kernel. This is the SPM default, optimal for group inference (Mikl et al., 2008) and commonly used in voxel-based morphometry studies (Smieskova et al., 2012; Shen and Sterr, 2013).

Before statistical analysis, an inclusion mask was created by absolute thresholding, which excluded all voxels with $G M$ values $<0.2$. Statistical analysis on processed GM images was performed by means of wholebrain multiple linear regression. Age, sex, and total intracranial volume were included as covariates. As in rsfMRI analysis, mean GM values were extracted for select ROIs (bilateral amygdala, insula, and auditory cortex) 
A
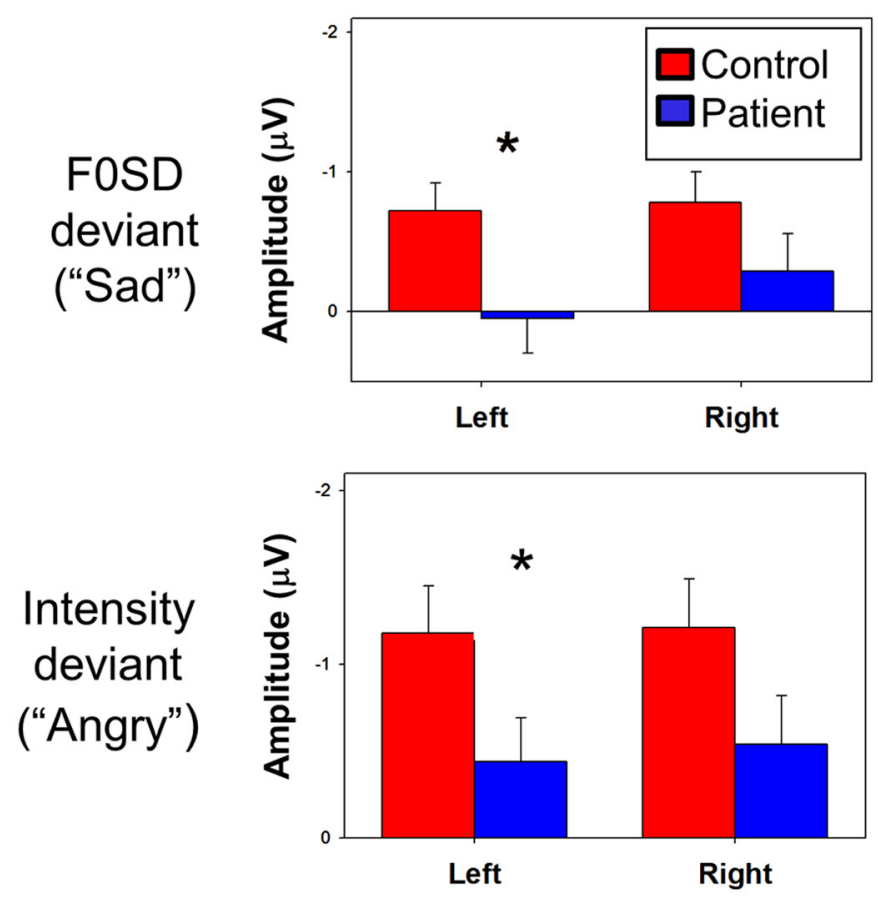

\section{Dual
FOM/F0SD
deviant
(No emotion)}

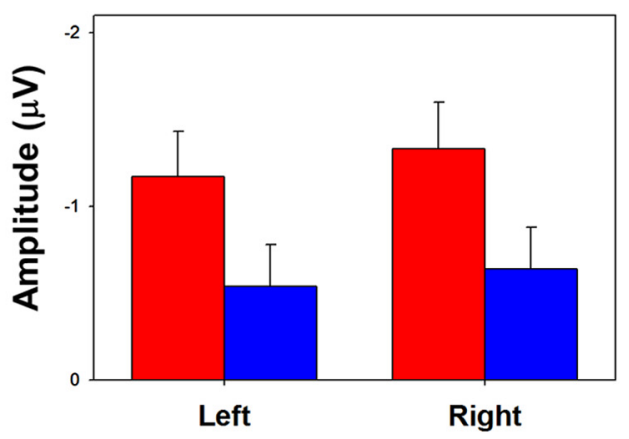

B

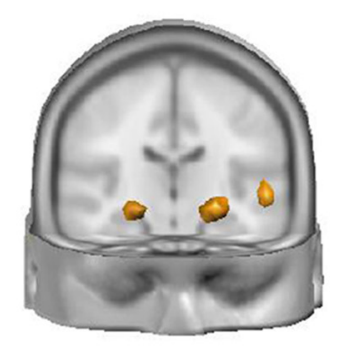

Control

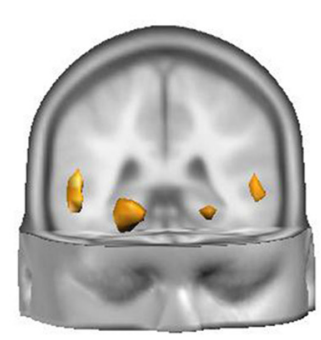

Control

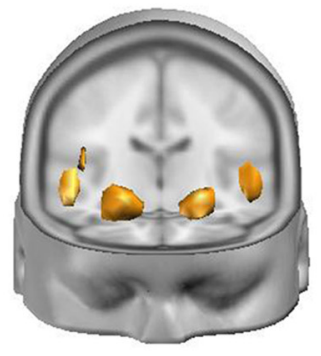

Control

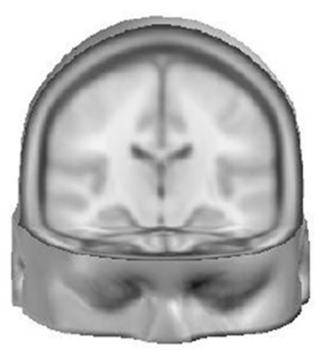

Patient

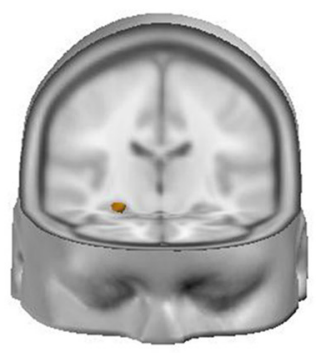

Patient

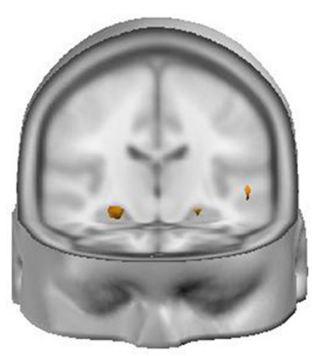

Patient

Figure 4. A, Mean amplitude over 160-250 ms latency window for MMN to MMN_FoSD deviants ("Sad," top), and MMN_Intensity deviants ("Angry," middle) or over 100-160 ms latency window to FOM/FOSD deviants (Dual, bottom). For FOSD $\left(F_{(1,77)}=3.5, p=0.06\right)$ and MMN_intensity $\left(F_{(1,77)}=3.5, p=0.06\right)$, the main effect of group was significant only at trend level, although significant unilateral surface deficits were seen for left-sided MMN_FOSD $\left(t_{(77)}=2.3, p=0.023\right)$ and MMN_intensity $\left(t_{(77)}=2.0, p=0.05\right)$. B, Source localization generated in LAURA for FOSD (top) at current density $338 \mu \mathrm{A} / \mathrm{mm}^{3}$, intensity at $318 \mu \mathrm{A} / \mathrm{mm}^{3}$ (middle), or FOM/FOSD at $315 \mu \mathrm{A} / \mathrm{mm}^{3}$ (bottom). ${ }^{*} p<0.05$ patients versus controls.

while adjusting for age, sex, and total intracranial volume using the SPM VOI toolbox.

Statistical analyses. Between-group tests for demographics were compared by a Mann-Whitney test for ordinal values and by independent-sample $t$ tests for continuous values. Primary analysis was conducted using mean (surface) MMN amplitude at the selected electrodes and latency windows (see MMN to FM tone analysis). Because no interactions were seen, individual electrode mean amplitudes were then averaged within hemisphere and deviant for subsequent analysis. Analysis of peak N1, source waveform, and rsfMRI analysis was secondary. An exploratory analysis assessed the relationship among measures.

Between-group effects were assessed using multivariate ANOVA (MANOVA/repeated-measure MANOVA) using within-subject factors of deviant type, electrode, and hemisphere and a between-subject factor of diagnostic group, with follow-up univariate ANOVA or independent-sample $t$ tests. Relationships among measures were determined by Pearson correlations and multivariate linear regression using bilateral MMN and rsfMRI. Within linear regression, overall $R^{2}$ values were used to assess overall model significance, whereas partial correlations were used to assess significance of association for indi- vidual variables. Effect size was calculated using Cohen's d, with cutoffs of $0.2,0.5$, and 0.8 for small, medium, and large effect size, respectively. Two-tailed statistics are used throughout with preset $\alpha$ level for significance of $p<0.05$. No group $\times$ gender interaction was seen for MMN $\left(F_{(1,75)}=0.0, p=0.99\right)$ or connectivity analysis $\left(F_{(3,99)}=0.25, p=0.87\right)$.

\section{Results}

\section{MMN to FM tones}

MMN to FM tone analysis was conducted in 43 patients and 36 controls. As in prior studies (Bishop et al., 2005; Leitman et al., 2011a), surface MMN activity occurred in the 100-160 ms latency window for F0M, F0M/F0SD, and HF500, and in the 160-250 ms window for F0SD, intensity and non-FM deviants (Figs. 3, 4). The difference in MMN latency for F0SD deviants relative to F0M or HF500 deviants most likely reflects the fact that base pitch can be detected at stimulus onset, whereas pitch variability over time can only be detected once sufficient sampling of the stimulus has occurred. This same difference in latency has 
been observed in prior studies (Bishop et al., 2005; Leitman et al., 2011a).

Surface analysis was conducted for each deviant using a repeated-measure MANOVA with within-subject factors of electrode and hemisphere and a between-subject factor of diagnostic group. Underlying MMN sources were identified using source localization (LAURA). Source strength was evaluated using a repeated-measure ANOVA with a within-subject factor of source and hemisphere and a between-subject factor of group.

For MMN to F0M deviants (MMN_F0M), between-group deficits were seen in surface (Fig. $3 A-C ; F_{(1,77)}=5.2, p=0.026$ ) analysis, with no electrode $\times$ group $\left(F_{(7,71)}=0.9, p=0.49\right)$, hemisphere $\times$ group $\left(F_{(1,77)}=0.2, p=0.65\right)$, or electrode $\times$ hemisphere $\times$ group interactions $\left(F_{(7,71)}=0.5, p=0.81\right)$. Between-group deficits were also seen in MMN_F0M source strength across auditory cortex and anterior insula sources (Fig. $3 D ; F_{(1,77)}=4.1, p=0.046$ ), again without source $\times$ group $\left(F_{(1,77)}=0.3, p=0.58\right)$, hemisphere $\times$ group $\left(F_{(1,77)}=2.7, p=\right.$ $0.1)$, or source $\times$ hemisphere $\times$ group interactions $\left(F_{(1,77)}=2.7\right.$, $p=0.11$.

For MMN_F0SD (Fig. $4 A, B$, top; $F_{(1,77)}=3.5, p=0.06$ ), MMN_intensity (Fig. $4 A, B$, middle; $F_{(1,77)}=3.6, p=0.06$ ), and MMN_F0M/F0SD $\left(F_{(1,77)}=3.7, p=0.06\right)$ (Fig. $4 A, B$, bottom), the main effect of group was significant only at trend level, although significant unilateral surface deficits were seen (Fig. $4 A)$. No between-group differences in MMN_HF500 were seen $\left(F_{(1,77)}=1.7, p=0.19\right)$. No significant group $\times$ electrode, group $\times$ hemisphere, or electrode $\times$ hemisphere $\times$ group interactions were seen. As with F0M, predominant generators localized to auditory cortex and insula (Fig. $4 B$ ), with a trend-level between-group difference in source strength seen for MMN_F0M/F0SD $\left(F_{(1,77)}=3.8, p=0.056\right)$ with no significant interaction effects (all $p>0.2$ ).

Because no interactions were seen, individual electrode amplitudes were averaged within hemisphere and deviant for further analysis. Across deviants, a strongly significant reduction in MMN amplitude in schizophrenia patients relative to controls was observed across all deviant types (main effects of group: $\left.F_{(1,77)}=8.3, p=0.005\right)$. As expected, the main effect of deviant type was also significant $\left(F_{(1,74)}=7.8, p<0.001\right)$, reflecting variation in MMN amplitude in response to the different deviants. However, the group $\times$ deviant type interaction was nonsignificant $\left(F_{(1,74)}=0.3, p=0.87\right)$, suggesting statistically similar levels of deficit across deviant types. The group $\times$ hemisphere interaction was also nonsignificant $\left(F_{(1,77)}=0.04, p=0.84\right)$.

For source waveforms, a significant difference was also observed across all deviant types (main effect of group: $F_{(1,77)}=5.9$, $p=0.017)$ along with a main effect of deviant type $\left(F_{(1,74)}=5.6\right.$, $p=0.001)$. In this analysis, the main effect of hemisphere $\left(F_{(1,77)}=4.6, p=0.034\right)$ and group $\times$ hemisphere $\times$ source interaction $\left(F_{(1,77)}=5.0, p=0.028\right)$ were also significant, with greatest deficit observed in the strength of the right insula source $\left(F_{(1,77)}=10.0, p=0.002\right)$.

\section{Behavioral results and behavior/MMN correlation}

AER analysis was conducted in 58 patients and 49 controls, including all 79 subjects who completed MMN to FM tones. As reported previously (Gold et al., 2012), patients showed significant deficits in both simple tone-matching $\left(t_{(111)}=5.6, p<\right.$ $0.001)$ and AER $\left(t_{(105)}=4.7, p<0.001\right)$ ability (Fig. $5 A$ ), and significant correlations were seen between tone-matching and total AER ability $(r=0.37, n=93, p<0.001)$. Between-group differences in AER remained significant after controlling for tone-matching $\left(F_{(1,90)}=5.2, p=0.026\right)$. When bilateral surface MMN_FOM amplitudes were entered simultaneously into a multiple regression analysis with AER as the dependent variable, the overall model was highly significant (overall $R^{2}=0.19, F_{(2,76)}=$ $8.7, n=79, p=0.001$ ), with the highest contribution from rightsided surface MMN_F0M waveforms $(r=-0.32, n=79$, $p=0.005$; Fig. $5 B$ ).

When tone matching was added to the model, the overall model was again highly significant (overall $R^{2}=0.26, F_{(3,66)}=$ 7.6, $p<0.001, n=70$; Fig. $5 C$ ), with significant independent contributions from right-sided surface MMN_F0M (partial $r=-0.37, p=0.002, n=70$ ) and tone matching (partial $r=$ $0.36, p=0.003, n=70$ ). Correlations with right-sided surface MMN_FOM remained strongly significant even after controlling for group status (partial $r=-0.33, p=0.006, n=70$ ).

\section{Correlation by feature}

As we have previously reported, variations in pitch and intensity may contribute independently to AER, with patients having particular difficulty in identifying emotion based upon pitch (Gold et al., 2012). Consistent with our prior report, within the present sample, a larger deficit was observed for pitch-based (e.g., F0M, FOSD; $\left.t_{(77)}=4.9, p<0.001, d=1.1\right)$, relative to intensity-based (e.g., intensity, HF500; $t_{(77)}=2.3, p=0.026, d=0.52$ ) AER performance, although the group $\times$ feature interaction was significant only at trend level $\left(F_{(1,77)}=3.1, p=0.08\right)$.

To evaluate the relative utility of physiological versus behavioral measures, separate analyses were conducted for MMN to pitch (MMN_FOM) features relative to AER feature subscores (Fig. 5A; AER by feature). As predicted, significant correlations were seen between amplitude of MMN_F0M and AER score to pitch-based stimuli (overall $R^{2}=0.10, F_{(2,76)}=4.1, p=0.02, n=$ 79). As with correlations to overall AER, correlations between MMN_FOM and pitch-based AER remained significant even after controlling for group status, with the highest contribution from right-sided surface MMN_F0M (partial $r=-0.27, p=$ $0.02, n=79$ ).

\section{FM tone identification}

FM tone identification analysis was conducted in 42 patients and 36 controls. Following completion of the ERP data collection, subjects were asked to identify the emotional percept most associated with each of the tones. As expected, controls identified tones used as F0M deviant stimuli primarily as happy, tones used as FOSD deviant stimuli primarily as sad, and tones used as HF500 deviants primarily as angry/fearful (Fig. 5D).

Patients were less likely than controls to identify F0M deviant tones as happy $\left(t_{(76)}=2.3, p=0.023\right)$ and FOSD tones as sad $\left(t_{(76)}=3.0, p=0.004\right)$, although they showed a similar response pattern to HF500 deviant stimuli $\left(t_{(76)}=1.5, p=0.14\right)$ (Fig. $5 D$ ). Across both groups, responses to both F0M/F0SD and standards were relatively evenly divided between emotions $\left(\chi^{2}=6.7\right.$, $p=0.15)$, consistent with the expected emotional ambiguity of these stimuli.

\section{Responses to standard stimuli}

$\mathrm{N} 1$ analysis was conducted in 43 patients and 36 controls. As expected (Bishop et al., 2005; Leitman et al., 2011a), when presented as standards (Fig. 2B), the stimuli elicited a frontocentral N1 response, with peak amplitudes at $\sim 150 \mathrm{~ms}$. Response amplitudes to the repetitive standards were small in both groups due to the short interstimulus interval with no significant difference in 

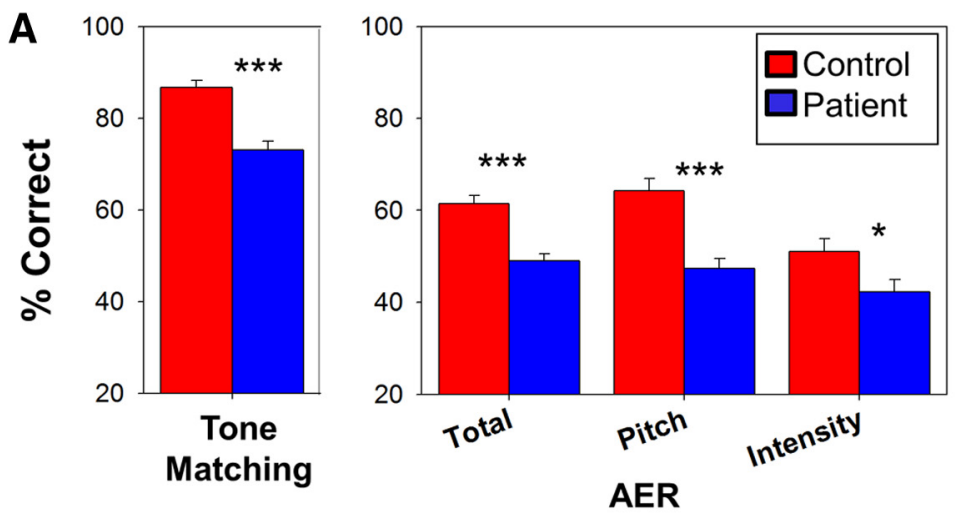

(by feature)

C

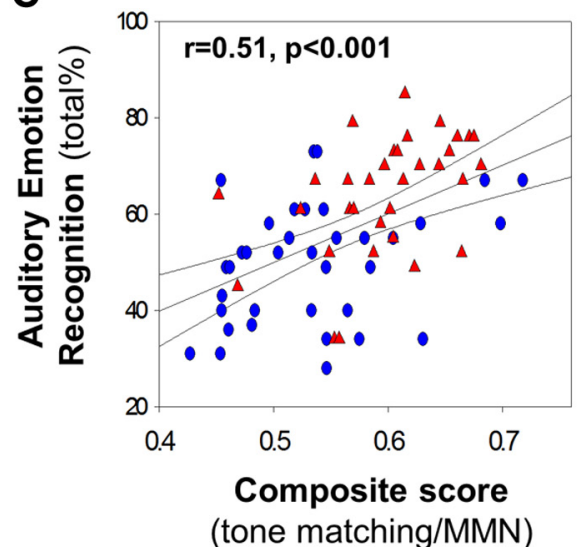

Control

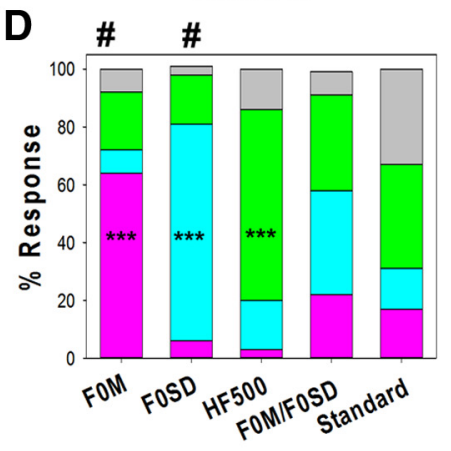

Deviant
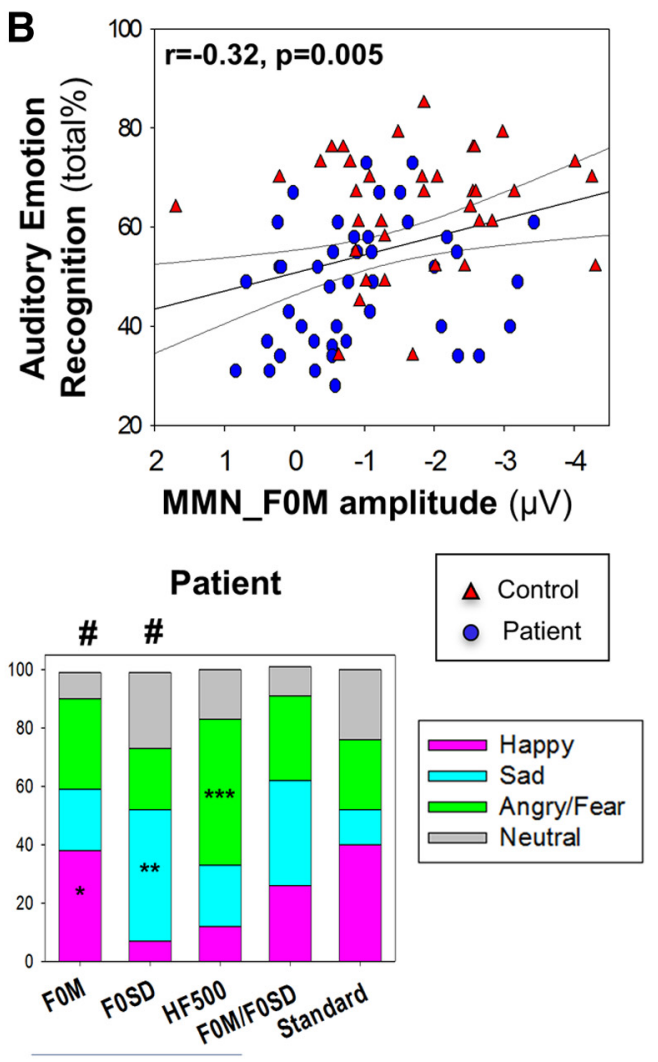

Figure 5. A, Bar graph (mean \pm SEM) of percentage correct for auditory and emotion processing tasks. AER: total, pitch, and intensity scores. $y$-axis is calibrated to start from chance performance. ${ }^{* * *} p<0.001$ (independent-samples $t$ test). ${ }^{*} p<0.05$ (independent-samples $t$ test). $B$, Scatter plot of total score for performance on auditory emotion recognition versus surface MMN_F0M. $C$, Scatter plot of total score for performance on auditory emotion recognition versus composite of tone-matching task and surface MMN_F0M. D, Stacked bar graphs noting percentage answered for listed deviants on FM-prosody task. Blue represents patients; red represents controls. ${ }^{* * *} p<0.001$ (one-samplet tests for hypothesized emotion). ${ }^{* *} p<0.01$ (one-sample t tests for hypothesized emotion). ${ }^{*} p<0.05$ (one-sample $t$ tests for hypothesized emotion). ${ }^{\#} p<0.05$ (between-group independent-sample $t$ test for most prevalent emotion). FOM, Happy; FOSD, sad.

Table 2. Response to standard stimuli in FCZ channel (N1)

\begin{tabular}{llllll}
\hline & \multicolumn{2}{l}{ Peak amplitude $^{a}$} & & \multicolumn{2}{l}{ Peak latency $^{a}$} \\
\cline { 2 - 3 } \cline { 5 - 6 } & Patient & Control & & Patient & Control \\
\hline FOM & $-1.3 \pm 1.3$ & $-1.3 \pm 1.3$ & & $145.8 \pm 44.1$ & $149.7 \pm 41.5$ \\
FOSD & $-1.4 \pm 1.1$ & $-1.3 \pm 1.3$ & & $138.0 \pm 44.7$ & $141.3 \pm 43.6$ \\
HF500 & $-1.0 \pm 1.5$ & $-1.2 \pm 1.1$ & & $136.2 \pm 41.7$ & $144.1 \pm 35.8$ \\
Intensity & $-1.0 \pm 1.3$ & $-1.2 \pm 1.4$ & & $135.0 \pm 43.3$ & $131.3 \pm 46.9$ \\
FOM/FOSD & $-1.5 \pm 1.0$ & $-1.5 \pm 1.1$ & & $138.0 \pm 36.0$ & $147.5 \pm 35.9$ \\
Non-FM & $-1.4 \pm 1.1$ & $-1.4 \pm 1.1$ & & $143.4 \pm 45.5$ & $149.8 \pm 32.7$ \\
\hline
\end{tabular}

${ }^{a}$ Response amplitudes $\left(F_{(1,77)}=0.008, p=0.93\right)$ and latencies $\left(F_{(1,77)}=0.38, p=0.54\right)$ were similar for patients and controls across stimulus types.

either N1 amplitudes $\left(F_{(1,77)}=0.008, p=0.93\right)$ and latencies $\left(F_{(1,77)}=0.38, p=0.54\right)$ between groups across stimulus types (Table 2).

The later N1 response to FM tones versus more typical auditory stimuli (e.g., clicks, simple tones) most likely reflects the much more gradual onset of FM tones versus the relative rapid onset (e.g., 5-10 ms on/off times) of tones typically used in N1 studies. Both the more gradual stimulus onset and the rapid rate may have contributed to the lack of significant between-group differences on the N1, consistent with a recent study (Pinheiro et al., 2013), which also did not find a significant deficit in N1 generation to "pure" prosody stimuli in schizophrenia, but this study did not assess MMN generation.

\section{rsfMRI}

rsfMRI analysis was conducted in 55 patients and 51 controls. To assess potential contributions of functional connectivity deficits between auditory cortex and insula to AER impairments, seeds were created in these regions based upon both known coordinates and LAURA source reconstructions (Fig. 6A). Because amygdala was adjacent to the insula source and is known to participate as well in emotional processing, an additional seed was created for amygdala and analyzed relative to both insula and auditory cortical dipoles.

Auditory cortex to insula connectivity

An initial pairwise analysis was conducted between the insula seed and both auditory cortex and amygdala. As predicted, significantly reduced connectivity was observed across pairwise connections between the insula and amygdala or auditory cortex in patients $\left(F_{(1,104)}=6.7, p=0.01\right.$; Fig. $\left.6 B\right)$, which remained significant even after controlling for technical factors, such as magnet type (1.5T or $3 \mathrm{~T})$ and framewise displacement $\left(F_{(1,102)}=7.3, p=0.008\right)$.

Specificity of our source localization model was also assessed by voxelwise rsfMRI analysis of the insula seeds (Fig. 6A, $B$ ). For right insula, the between-group difference region included the bilateral auditory cortex $\left(t_{(104)}=3.8, p<0.001\right)$. For left insula, the difference region included the left $\left(t_{(104)}=3.1, p=0.003\right)$, but not the right auditory cortex (not significant; Fig. 6A). No significant difference in cortical volume was seen across the six 
A

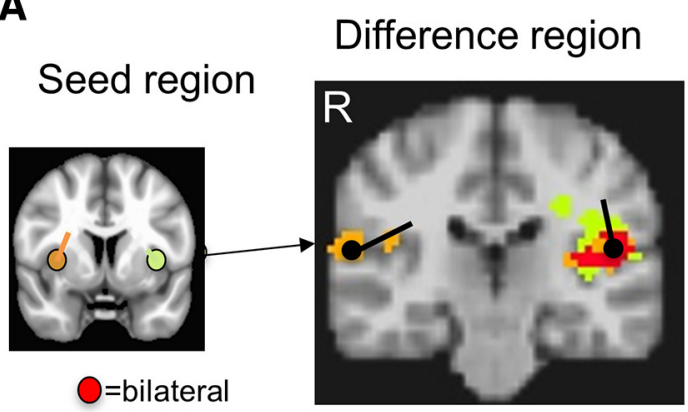

B

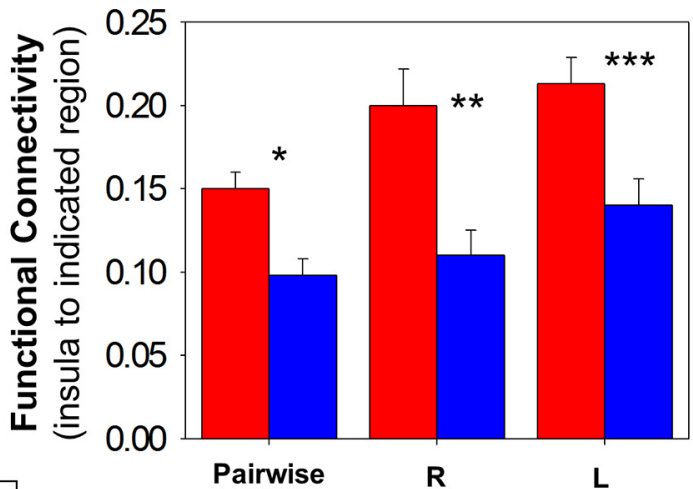

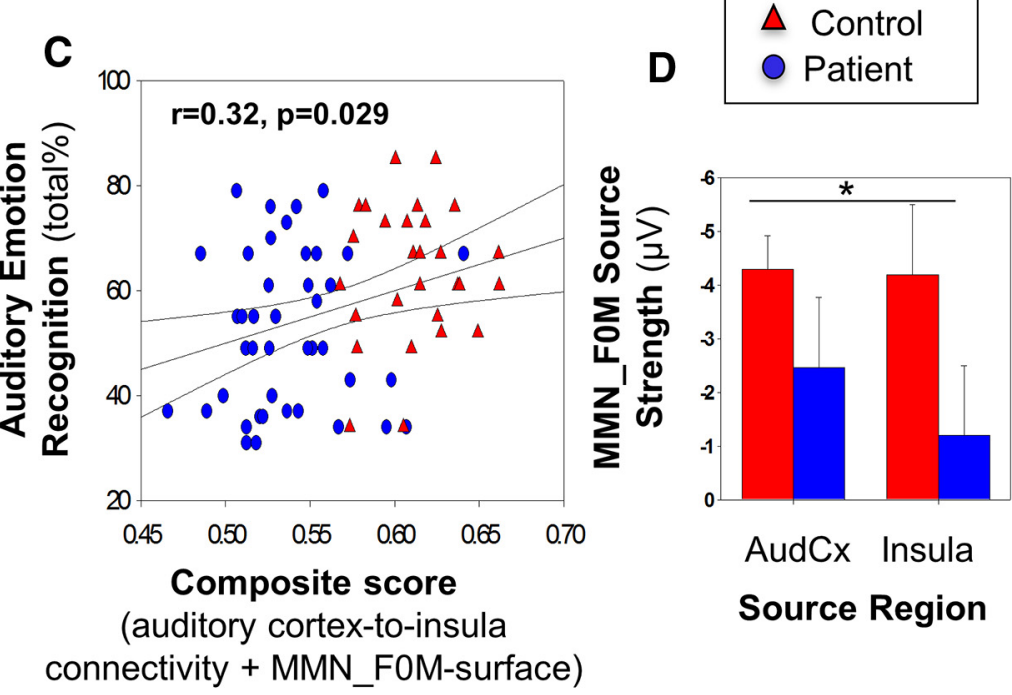

E

(amygdala to insula) Voxelwise

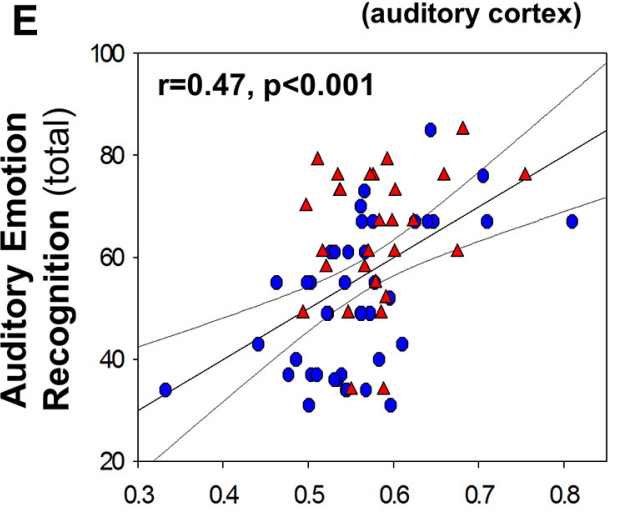

Composite score

(auditory cortex-to-insula connectivity + MMN_FOM source)

Figure 6. A, Seed and difference regions (controls greater than patients) of voxelwise functional connectivity between insula and bilateral auditory cortex. Maps are thresholded at $p<0.05$, corrected for multiple comparisons. Location and orientation of source derived dipoles generated in BESA 5.3 are shown, with medial temporal cortex dipoles shown in seed region inset color coded for right (orange), left (green), and bilateral (red). Orientation of dipoles is based on BESA analysis. B, Bar graph of pairwise and voxelwise functional connectivity between insula and auditory cortex dipole. C, Scatter plot of total score for performance on auditory emotion recognition versus composite of voxelwise functional connectivity between insula and auditory cortex + surface MMN_FOM. D, Bar graph of MMN_FOM source strength. $\boldsymbol{E}$,Scatter plot of total score for performance on auditory emotion recognition versus composite of voxelwise functional connectivity between insula and auditory cortex + source MMN_FoM. Blue represents patients; red represents controls. ${ }^{* * *} p<0.001 .{ }^{* *} p<0.01 .{ }^{*} p<0.05$. AudCx, Auditory Cortex.

Table 3. Cortical volume (gray matter volume, $\left.\mathrm{m}^{3}\right)^{a}$

\begin{tabular}{lll}
\hline & Patient & Control \\
\hline Left PT & $0.42 \pm 0.05$ & $0.41 \pm 0.05$ \\
Right PT & $0.38 \pm 0.04$ & $0.40 \pm 0.04$ \\
Left MTC & $0.63 \pm 0.04$ & $0.64 \pm 0.05$ \\
Right MTC & $0.61 \pm 0.04$ & $0.61 \pm 0.04$ \\
Left amygdala & $0.60 \pm 0.03$ & $0.61 \pm 0.03$ \\
Right amygdala & $0.54 \pm 0.03$ & $0.54 \pm 0.02$ \\
\hline
\end{tabular}

${ }^{a}$ No significant difference in cortical volume was seen across the six $\operatorname{ROls}\left(F_{(1,85)}=0.8, p=0.37\right)$ between groups. PT, Planum temporal; MTC, medial temporal cortex (anterior insula).

ROIs $\left(F_{(1,85)}=0.8, p=0.37\right)$ between groups (Table 3$)$, suggesting that these connectivity differences were not due to volume reductions within these regions.

Significant correlations were seen between AER and auditory cortex-to-insula connectivity (overall $R^{2}=0.11, F_{(2,62)}=3.9, p=$ $0.027, n=63)$. The overall model remained significant after controlling for group ( $p=0.018, n=63)$. The correlation between rightsided auditory cortex-to-insula connectivity and AER was also individually significant $(r=0.33, p=0.008, n=63)$.

Relationship between neurophysiological and functional imaging measures

The relationship between MMN and rsfMRI was assessed in the subset of subjects with both measures available ( 21 controls, 14 patients). For this analysis, we focused on the relative contributions of impaired MMN generation and impaired auditory cortex-to-insula connectivity to overall impairments in AER.

When bilateral MMN_F0M (surface) and auditory cortex-toinsula connectivity were entered simultaneously into a multiple regression analysis with AER as the dependent variable, the overall model was significant (overall $R^{2}=0.10, F_{(2,67)}=3.7, p=$ $0.029, n=35$; Fig. $6 C$ ), with both $\mathrm{MMN}$ amplitude (partial $r=-0.24, p=0.05, n=35$ ) and connectivity (partial $r=0.24$, $p=0.05, n=35$ ) showing independent correlations in the expected directions (reduced MMN and reduced functional connectivity $\rightarrow$ greater impairment in AER). Moreover when MMN_F0M source strength (Fig. 6D) was entered instead of MMN_F0M surface amplitude, the overall model showed an even stronger relationship to AER (overall $R^{2}=0.22, F_{(3,66)}=$ $6.3, p=0.001, n=35$; Fig. $6 E$ ), with the MMN_F0M auditory source contributing independently (partial $r=-0.37, p=0.002$, $n=35$ ).

Simple tone MMN and relationship with AER

Simple tone MMN analysis was conducted in 28 patients and 23 controls who had also participated in a prior study (Friedman et al., 2012). In this subset, highly significant between-group differences in MMN to simple, non-FM tones were seen (Fig. 7A,B), 
A

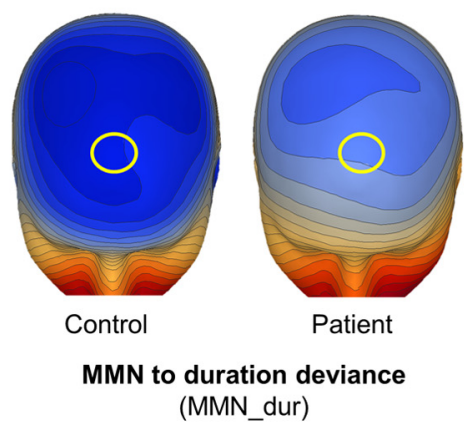

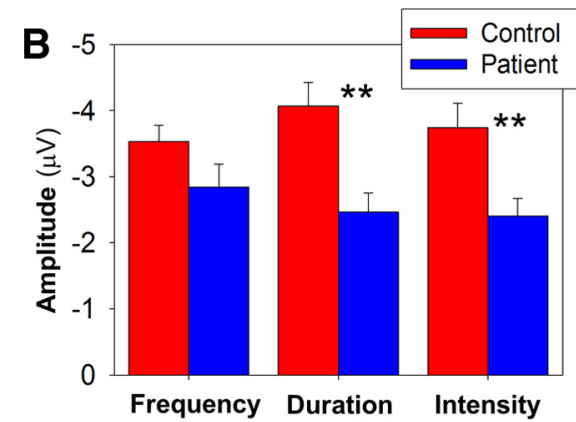

E

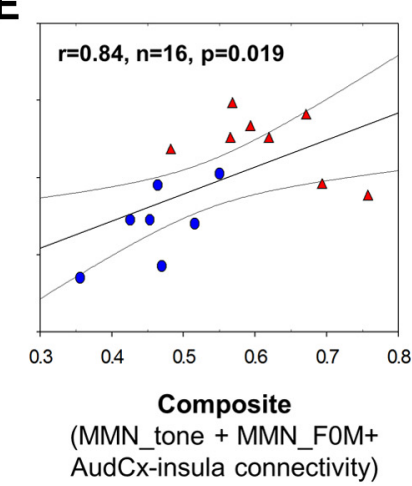

Figure 7. A, Voltage topography maps for MMN to duration deviant (174 ms, $16 \mu \mathrm{V} / \mathrm{step})$ for available patients $(n=30)$ and controls $(n=25)$. Yellow circle represents location of analyzed electrodes. $\boldsymbol{B}$, Bar graph (mean \pm SEM) of peak amplitude for simple tone deviants. C, Scatter plot of total score for performance on auditory emotion recognition versus mean amplitude across the three tested features. $\boldsymbol{D}$, Scatter plot of total score for performance on auditory emotion recognition versus composite of surface MMN_FOM and MMN to simple tone deviants. D, Scatter plot of total score for performance on auditory emotion recognition versus composite of surface MMN_FOM and MMN to simple tone deviants. $E$, Scatter plot of total score for performance on auditory emotion recognition versus composite of surface MMN_FOM, pairwise functional connectivity between insula, and auditory cortex and MMN to simple tone deviants. Blue represents patients; red represents controls. ${ }^{* *} p<0.01$. AudC $x$, Auditory Cortex.

consistent with the larger study. In contrast to MMN_F0M, the relationship between AER and MMN to features (i.e., pitch/duration/intensity) of simple tones was significant at a trend level only (Fig. 7C).

By contrast, when MMN_F0M was added to the regression, the level of correlation increased significantly, with the combination of MMN to simple tones and MMN_F0M deviants accounting for $\sim 47 \%$ of the variance in AER performance (overall $R^{2}=$ $0.47, F_{(5,25)}=4.4, p=0.005, n=31$; Fig. $\left.7 D\right)$. In the combined regression, the largest contribution was from MMN_F0M (partial $r=-0.55, p=0.003, n=31$ ), whereas MMN to simple tonal features did not contribute significantly $(r=-0.29$ to 0.22 , all $p>0.14, n=31$ ).

Finally, when MMN to simple tones, right-sided MMN_F0M, and pairwise auditory cortex-to-insula connectivity were entered simultaneously into a multiple regression analysis with AER as the dependent variable, a further increase in the level of correlation was seen (overall $R^{2}=0.70, F_{(5,10)}=4.6, p=0.019, n=16$; Fig. $7 E)$. Despite the limited sample size in this model $(n=16)$, MMN_F0M (partial $r=-0.73, p=0.008, n=16$ ) remained independently significant.

\section{Discussion}

Deficits in AER ability are consistently demonstrated in schizophrenia and, along with deficits in face emotion recognition, contribute significantly to impairments in social cognition and global functional outcome (Penn et al., 2008; Leitman et al., 2010; Gold et al., 2012). The underlying neural mechanisms, however, remain incompletely understood. The present study used a multimodal ERP/fMRI approach to localize neural substrates underlying impaired AER in schizophrenia.

Key findings were as follows: (1) impaired processing of emotionally relevant FM stimulus features (MMN to FM tones) occurred even for stimuli that were unattended at the time of stimulus presentation, suggesting deficits even in preattentive sensory processing; and (2) impairments were observed not only in initial processing as reflected in MMN, but also impaired functional connectivity between the auditory cortex and anterior insula. The present study thus extends prior research showing auditory cortex-level dysfunction in schizophrenia using simple tone MMN (Garrido et al., 2009; Friedman et al., 2012; Light et al., 2012) and tone matching (Javitt and Sweet, 2015). In addition, the study validates FM tone-based approaches for physiological investigation of AER deficits across neuropsychiatric disorders.

Although relatively few studies have evaluated MMN specifically in response to FM tones (Bishop et al., 2005; Leitman et al., 2011a), the basic MMN phenomenon was first demonstrated $>20$ years ago, when it was demonstrated that preattentive detection of stimulus novelty predicted subsequent attentiondependent detection (Tiitinen et al., 1994). The phenomenon, initially termed "primitive intelligence," likely represents local circuit interactions within the auditory cortex, including the ability to encode and maintain modality-specific memory traces, and the ability of deviance detectors to detect alterations in an ongoing pattern of stimulation (Näätänen et al., 2001).

At present, several neural models have been proposed to account for MMN generation, including models focusing on adap- 
tion, model adjustment, or predictive coding concepts (for review, see Garrido et al., 2009; Javitt and Freedman, 2015; Javitt and Sweet, 2015). For the present study, we explicitly included an adaptation control approach using "like from like" comparisons to minimize differential adaptation. Our findings of networklevel interaction between auditory-cortex and insula during MMN generation to FM tones is analogous to prior studies showing network interaction between auditory and right inferior frontal gyrus during processing of simple amplitude modulated tones (Garrido et al., 2009).

The present findings thus support earlier neurophysiological and predictive coding models and suggest that interactions between auditory cortex and medial temporal regions, especially insula, may be critical in processing emotion-related stimuli. In fMRI studies of MMN to simple tones, differential activation patterns are observed in temporal and frontal regions relative to levels of pitch change (Doeller et al., 2003). Future parametric studies of MMN to FM-deviant tones are required to determine whether or not a similar relationship is observed between auditory cortex and insula in processing of prosodic-related information.

A relationship between impaired MMN generation to simple pitch features (i.e., non-FM tones) and AER dysfunction has also been previously reported (Jahshan et al., 2013), and is supported in the present study (Fig. 7C). Nevertheless, we observed a significantly stronger correlation when both MMN to FM tones were entered into the regression along with simple tone MMN, with the two variables together accounting for $\sim 50 \%$ of the variance in AER across subjects (Fig. 7D). Thus, these findings support the concept that the ability to discriminate FM-related features may be more proximate to AER function than the ability to discriminate simpler features, and thus may permit more detailed interrogation of underlying neural circuits.

In addition to showing associations between impaired MMN to FM tones and impaired AER function, the present study demonstrates a significant correlation between impaired AER ability and impaired functional connectivity between auditory and anterior insula cortex. In general, ERP possesses high temporal resolution but low spatial resolution. Thus, they are well suited to tracing flow of information across brain regions. However, localizing the regions involved in information flow is difficult using surface EEG data. By contrast, fMRI possesses high spatial resolution but low temporal resolution, and is thus well suited for exploring interactions among discrete brain regions.

In the present study, the dipole solution from the ERP study was used to create seeds for connectivity (rsfMRI) analysis. Primary MMN sources were observed in auditory cortex and anterior insula. In rsfMRI analysis, we observed a significant reduction in functional connectivity between these regions in patients relative to controls ( $p<0.01$; Fig. $6 B$ ). The deficit, moreover, correlated highly with the degree of AER impairment $(r=0.33)$.

Finally, when both MMN and functional connectivity measures were entered into a simultaneous regression versus AER, both contributed significantly (Fig. 6C,E), suggesting that both preattentive auditory processing and impaired connectivity contribute independently to the overall pattern of AER deficit in schizophrenia. These findings complement prior studies showing impaired connectivity between auditory cortex and inferior frontal gyrus during emotion processing (Leitman et al., 2011b), and potentially suggest a more generalized role of auditory-cortical dysconnectivity in the pathogenesis of schizophrenia.
Our findings also add to a growing literature implicating the anterior insula both in AER processing and in schizophrenia. For example, several studies in healthy controls have shown insula activation to nonverbal or pseudo-word emotional stimuli (Morris et al., 1999; Bach et al., 2008; Thönnessen et al., 2010). In parallel, significant reduction has been observed in anterior insula volume in schizophrenia (Shepherd et al., 2012). The present is the first study to demonstrate insula activation by emotionrelevant FM tones, and also the first to demonstrate reductions in auditory cortex-to-insula connectivity during emotion processing in schizophrenia. In the present study, we detected significant deficits not only in right auditory cortex to right insula, but also a significant cross-hemisphere connectivity deficit in left auditory cortex and right insula, suggesting that right insula may be particularly involved in the pathophysiology of schizophrenia (Moran et al., 2013; Ruiz et al., 2013; Manoliu et al., 2014) and AER dysfunction (Pichon and Kell, 2013).

Although no intervention was included in the present study, the present study suggests that auditory training strategies targeted at deficits in detecting pitch and intensity modulation of FM tones within the prosodic speech range (e.g., $100-400 \mathrm{~Hz}$ ) may be most relevant to remediation of AER impairments. Although remediation of ability to detect AER-related tonal contours will not, of itself, restore connectivity or normalize function, it may be a critical first step to permitting patients to benefit from AER training, which, in turn, would be critical to normalization of social interaction.

\section{Circular analysis issues}

As detailed in Materials and Methods, we followed published guidelines (Kriegeskorte et al., 2009) to prevent "circular analysis" ("double-dipping") bias, which can occur when hypotheses (e.g., prediction of between-group differences) are used to set conditions for the analysis. The general analysis plan was based upon a prior methods-only study, which established the basic phenomenon (i.e., MMN to FM deviants) (Leitman et al., 2011a), with adjustments based on the magnitude of response based on the within controls or across the two groups ("A + B"), rather than the difference ("A - B"). Similarly, rsfMRI ROIs were based upon all available data incorporating a dataset considerably larger than those used for correlational analyses and thus were not influenced by the correlational hypotheses within the electrophysiology subgroup. Thus, while independent replication of the present findings would be desirable, we feel that the study was adequately protected against circular analysis concerns.

\section{Limitations}

Other potential limitations of the present study are that all patients were on antipsychotic medication, were in a relatively chronic phase of their illness, and were predominantly male. AER deficits have been observed in individuals at high symptomatic risk for schizophrenia even before illness onset (Amminger et al., 2012; Corcoran et al., 2015), suggesting that such deficits are likely present early in the course of the disorder and are independent from subsequent treatment. Finally, not all subjects participated in all components of the study. Thus, while the full sample is extensive (84 patients, 66 controls), the number of subjects with both sets of measures is more modest (14 patients, 21 controls). Nevertheless, despite the limited sample size, significant independent contributions of MMN and rsfMRI to impaired AER were detected.

In conclusion, the present study provides the first demonstration of impaired preattentive processing of AER-related FM tonal 
modulations in schizophrenia and the first demonstration of a link between impaired auditory/anterior insula connectivity and impaired affective processing. These findings demonstrate both specific bottom-up contributions and specific network-level contributions to impaired AER performance and anterior insula activations in schizophrenia and highlight the potential role of medial temporal structures, particularly right anterior insula, along with auditory cortex in social cognitive pathology in schizophrenia.

\section{References}

Amminger GP, Schafer MR, Klier CM, Schlogelhofer M, Mossaheb N, Thompson A, Bechdolf A, Allott K, McGorry PD, Nelson B (2012) Facial and vocal affect perception in people at ultra-high risk of psychosis, first-episode schizophrenia and healthy controls. Early Intervent Psychiatry 6:450-454. CrossRef Medline

Ashburner J (2007) A fast diffeomorphic image registration algorithm. Neuroimage 38:95-113. CrossRef Medline

Ashburner J, Friston KJ (2000) Voxel-based morphometry: the methods. Neuroimage 11:805-821. CrossRef Medline

Ashburner J, Friston KJ (2005) Unified segmentation. Neuroimage 26:839851. CrossRef Medline

Bach DR, Grandjean D, Sander D, Herdener M, Strik WK, Seifritz E (2008) The effect of appraisal level on processing of emotional prosody in meaningless speech. Neuroimage 42:919-927. CrossRef Medline

Bach DR, Buxtorf K, Strik WK, Neuhoff JG, Seifritz E (2011) Evidence for impaired sound intensity processing in schizophrenia. Schizophr Bull 37:426-431. CrossRef Medline

Banse R, Scherer KR (1996) Acoustic profiles in vocal emotion expression. J Pers Soc Psychol 70:614-636. CrossRef Medline

Bestelmeyer PE, Maurage P, Rouger J, Latinus M, Belin P (2014) Adaptation to vocal expressions reveals multistep perception of auditory emotion. J Neurosci 34:8098-8105. CrossRef Medline

Bishop DV, O’Reilly J, McArthur GM (2005) Electrophysiological evidence implicates automatic low-level feature detectors in perceptual asymmetry. Brain Res Cogn Brain Res 24:177-179. CrossRef Medline

Bleuler E (1950) Dementia praecox or the group of schizophrenias. New York: International Universities.

Chao-Gan Y, Yu-Feng Z (2010) DPARSF: a MATLAB Toolbox for "pipeline" data analysis of resting-state fMRI. Front Syst Neurosci 4:13. CrossRef Medline

Corcoran CM, Keilp JG, Kayser J, Klim C, Butler PD, Bruder GE, Gur RC, Javitt DC (2015) Emotion recognition deficits as predictors of transition in individuals at clinical high risk for schizophrenia: a neurodevelopmental perspective. Psychol Med 45:2959-2973. CrossRef Medline

Deserno L, Sterzer P, Wüstenberg T, Heinz A, Schlagenhauf F (2012) Reduced prefrontal-parietal effective connectivity and working memory deficits in schizophrenia. J Neurosci 32:12-20. CrossRef Medline

Doeller CF, Opitz B, Mecklinger A, Krick C, Reith W, Schröger E (2003) Prefrontal cortex involvement in preattentive auditory deviance detection: neuroimaging and electrophysiological evidence. Neuroimage 20: 1270-1282. CrossRef Medline

Edwards J, Pattison PE, Jackson HJ, Wales RJ (2001) Facial affect and affective prosody recognition in first-episode schizophrenia. Schizophr Res 48:235-253. CrossRef Medline

First M, Gibbon M, Spitzer R, Williams J (1996) User's guide for the structured clinical interview for DSM IV Axis I disorders clinician version (SCID I, Version 2.0). New York: Biometrics Research.

Friedman T, Sehatpour P, Dias E, Perrin M, Javitt DC (2012) Differential relationships of mismatch negativity and visual P1 deficits to premorbid characteristics and functional outcome in schizophrenia. Biol Psychiatry 71:521-529. CrossRef Medline

Garrido MI, Kilner JM, Stephan KE, Friston KJ (2009) The mismatch negativity: a review of underlying mechanisms. Clin Neurophysiol 120: 453-463. CrossRef Medline

Gil-da-Costa R, Stoner GR, Fung R, Albright TD (2013) Nonhuman primate model of schizophrenia using a noninvasive EEG method. Proc Natl Acad Sci U S A 110:15425-15430. CrossRef Medline

Gold R, Butler PD, Revheim N, Leitman DI, Hansen JA, Gur RC, Kantrowitz JT, Laukka P, Juslin PN, Silipo GS, Javitt DC (2012) Auditory emotion recognition impairments in schizophrenia: relationship to acoustic features and cognition. J Psychiatry 169:424-432. CrossRef Medline

Green MF, Kern RS, Braff DL, Mintz J (2000) Neurocognitive deficits and functional outcome in schizophrenia: are we measuring the "right stuff?" Schizophr Bull 26:119-136.

Gunduz-Bruce H, Reinhart RM, Roach BJ, Gueorguieva R, Oliver S, D’Souza DC, Ford JM, Krystal JH, Mathalon DH (2012) Glutamatergic modulation of auditory information processing in the human brain. Biol Psychiatry 71:969-977. CrossRef Medline

Heekeren K, Daumann J, Neukirch A, Stock C, Kawohl W, Norra C, Waberski TD, Gouzoulis-Mayfrank E (2008) Mismatch negativity generation in the human 5HT2A agonist and NMDA antagonist model of psychosis. Psychopharmacology 199:77-88. CrossRef Medline

Hoptman MJ, Antonius D, Mauro CJ, Parker EM, Javitt DC (2014) Cortical thinning, functional connectivity, and mood-related impulsivity in schizophrenia: relationship to aggressive attitudes and behavior. J Psychiatry 171:939-948. CrossRef Medline

Jahshan C, Wynn JK, Green MF (2013) Relationship between auditory processing and affective prosody in schizophrenia. Schizophr Res 143: 348-353. CrossRef Medline

Javitt DC (2009) Sensory processing in schizophrenia: neither simple nor intact. Schizophr Bull 35:1059-1064. CrossRef Medline

Javitt DC, Freedman R (2015) Sensory processing dysfunction in the personal experience and neuronal machinery of schizophrenia. J Psychiatry 172:17-31. CrossRef Medline

Javitt DC, Sweet RA (2015) Auditory dysfunction in schizophrenia: integrating clinical and basic features. Nat Rev Neurosci 16:535-550. CrossRef Medline

Javitt DC, Steinschneider M, Schroeder CE, Vaughan HG Jr, Arezzo JC (1994) Detection of stimulus deviance within primate primary auditory cortex: intracortical mechanisms of mismatch negativity (MMN) generation. Brain Res 667:192-200. CrossRef Medline

Javitt DC, Steinschneider M, Schroeder CE, Arezzo JC (1996) Role of cortical $\mathrm{N}$-methyl-D-aspartate receptors in auditory sensory memory and mismatch negativity generation: implications for schizophrenia. Proc Natl Acad Sci U S A 93:11962-11967. CrossRef Medline

Javitt DC, Schoepp D, Kalivas PW, Volkow ND, Zarate C, Merchant K, Bear MF, Umbricht D, Hajos M, Potter WZ, Lee CM (2011) Translating glutamate: from pathophysiology to treatment. Sci Transl Med 3:102mr102. CrossRef Medline

Jenkinson M, Bannister P, Brady M, Smith S (2002) Improved optimization for the robust and accurate linear registration and motion correction of brain images. Neuroimage 17:825-841. CrossRef Medline

Juslin PN, Laukka P (2001) Impact of intended emotion intensity on cue utilization and decoding accuracy in vocal expression of emotion. Emotion 1:381-412. CrossRef Medline

Kantrowitz JT, Leitman DI, Lehrfeld JM, Laukka P, Juslin PN, Butler PD, Silipo G, Javitt DC (2013) Reduction in tonal discriminations predicts receptive emotion processing deficits in schizophrenia and schizoaffective disorder. Schizophr Bull 39:86-93. CrossRef Medline

Kantrowitz JT, Hoptman MJ, Leitman DI, Silipo G, Javitt DC (2014a) The $5 \%$ difference: early sensory processing predicts sarcasm perception in schizophrenia and schizo-affective disorder. Psychol Med 44:25-36. CrossRef Medline

Kantrowitz JT, Scaramello N, Jakubovitz A, Lehrfeld JM, Laukka P, Elfenbein HA, Silipo G, Javitt DC (2014b) Amusia and protolanguage impairments in schizophrenia. Psychol Med 44:2739-2748. CrossRef Medline

Kay SR, Fiszbein A, Opler LA (1987) The positive and negative syndrome scale (PANSS) for schizophrenia. Schizophr Bull 13:261-276. CrossRef Medline

Kriegeskorte N, Simmons WK, Bellgowan PS, Baker CI (2009) Circular analysis in systems neuroscience: the dangers of double dipping. Nat Neurosci 12:535-540. CrossRef Medline

Le J, Lu M, Pellouchoud E, Gevins A (1998) A rapid method for determining standard 10/10 electrode positions for high resolution EEG studies. Electroencephalogr Clin Neurophysiol 106:554-558. CrossRef Medline

Leitman DI, Hoptman MJ, Foxe JJ, Saccente E, Wylie GR, Nierenberg J, Jalbrzikowski M, Lim KO, Javitt DC (2007) The neural substrates of impaired prosodic detection in schizophrenia and its sensorial antecedents. J Psychiatry 164:474-482. Medline

Leitman DI, Laukka P, Juslin PN, Saccente E, Butler P, Javitt DC (2010) Getting the cue: sensory contributions to auditory emotion recognition 
impairments in schizophrenia. Schizophr Bull 36:545-556. CrossRef Medline

Leitman DI, Sehatpour P, Garidis C, Gomez-Ramirez M, Javitt DC (2011a) Preliminary evidence of preattentive distinctions of frequencymodulated (FM) tones that convey affect. Front Hum Neurosci 5:96. CrossRef Medline

Leitman DI, Wolf DH, Laukka P, Ragland JD, Valdez JN, Turetsky BI, Gur RE, Gur RC (2011b) Not pitch perfect: sensory contributions to affective communication impairment in schizophrenia. Biol Psychiatry 70: 611-618. CrossRef Medline

Light GA, Swerdlow NR, Rissling AJ, Radant A, Sugar CA, Sprock J, Pela M, Geyer MA, Braff DL (2012) Characterization of neurophysiologic and neurocognitive biomarkers for use in genomic and clinical outcome studies of schizophrenia. PLoS One 7:e39434. CrossRef Medline

Manoliu A, Riedl V, Zherdin A, Mühlau M, Schwerthöffer D, Scherr M, Peters H, Zimmer C, Förstl H, Bäuml J, Wohlschläger AM, Sorg C (2014) Aberrant dependence of default mode/central executive network interactions on anterior insular salience network activity in schizophrenia. Schizophr Bull 40:428-437. CrossRef Medline

Michel CM, Murray MM, Lantz G, Gonzalez S, Spinelli L, Grave de Peralta R (2004) EEG source imaging. Clin Neurophysiol 115:2195-2222. CrossRef Medline

Mikl M, Marecek R, Hlustík P, Pavlicová M, Drastich A, Chlebus P, Brázdil M, Krupa P (2008) Effects of spatial smoothing on fMRI group inferences. Magn Reson Imaging 26:490-503. CrossRef Medline

Moran LV, Tagamets MA, Sampath H, O’Donnell A, Stein EA, Kochunov P, Hong LE (2013) Disruption of anterior insula modulation of large-scale brain networks in schizophrenia. Biol Psychiatry 74:467-474. CrossRef Medline

Morris JS, Scott SK, Dolan RJ (1999) Saying it with feeling: neural responses to emotional vocalizations. Neuropsychologia 37:1155-1163. CrossRef Medline

Mukherjee P, Whalley HC, McKirdy JW, McIntosh AM, Johnstone EC, Lawrie SM, Hall J (2012) Lower effective connectivity between amygdala and parietal regions in response to fearful faces in schizophrenia. Schizophr Res 134:118-124. CrossRef Medline

Murray MM, Brunet D, Michel CM (2008) Topographic ERP analyses: a step-by-step tutorial review. Brain Topogr 20:249-264. CrossRef Medline

Näätänen R, Picton T (1987) The N1 wave of the human electric and magnetic response to sound: a review and an analysis of the component structure. Psychophysiology 24:375-425. CrossRef Medline

Näätänen R, Tervaniemi M, Sussman E, Paavilainen P, Winkler I (2001) "Primitive intelligence" in the auditory cortex. Trends Neurosci 24: 283-288. CrossRef Medline

Näätänen R, Pakarinen S, Rinne T, Takegata R (2004) The mismatch negativity (MMN): towards the optimal paradigm. Clin Neurophysiol 115: 140-144. CrossRef Medline

Penn DL, Sanna LJ, Roberts DL (2008) Social cognition in schizophrenia: an overview. Schizophr Bull 34:408-411. CrossRef Medline

Petkova E, Lu F, Kantrowitz J, Sanchez JL, Lehrfeld J, Scaramello N, Silipo G, DiCostanza J, Ross M, Su Z, Javitt DC, Butler PD (2014) Auditory tasks for assessment of sensory function and affective prosody in schizophrenia. Compr Psychiatry 55:1862-1874. CrossRef Medline

Pichon S, Kell CA (2013) Affective and sensorimotor components of emotional prosody generation. J Neurosci 33:1640-1650. CrossRef Medline

Pinheiro AP, Del Re E, Mezin J, Nestor PG, Rauber A, McCarley RW, Gonçalves OF, Niznikiewicz MA (2013) Sensory-based and higherorder operations contribute to abnormal emotional prosody processing in schizophrenia: an electrophysiological investigation. Psychol Med 43: 603-618. CrossRef Medline
Power JD, Barnes KA, Snyder AZ, Schlaggar BL, Petersen SE (2012) Spurious but systematic correlations in functional connectivity MRI networks arise from subject motion. Neuroimage 59:2142-2154. CrossRef Medline

Revheim N, Corcoran CM, Dias E, Hellmann E, Martinez A, Butler PD, Lehrfeld JM, DiCostanzo J, Albert J, Javitt DC (2014) Reading deficits in schizophrenia and individuals at high clinical risk: relationship to sensory function, course of illness, and psychosocial outcome. J Psychiatry 171: 949-959. CrossRef Medline

Ruiz S, Lee S, Soekadar SR, Caria A, Veit R, Kircher T, Birbaumer N, Sitaram R (2013) Acquired self-control of insula cortex modulates emotion recognition and brain network connectivity in schizophrenia. Hum Brain Mapp 34:200-212. CrossRef Medline

Sehatpour P, Molholm S, Javitt DC, Foxe JJ (2006) Spatiotemporal dynamics of human object recognition processing: an integrated high-density electrical mapping and functional imaging study of "closure" processes. Neuroimage 29:605-618. CrossRef Medline

Shen S, Sterr A (2013) Is DARTEL-based voxel-based morphometry affected by width of smoothing kernel and group size? A study using simulated atrophy. J Magn Reson Imaging 37:1468-1475. CrossRef Medline

Shepherd AM, Matheson SL, Laurens KR, Carr VJ, Green MJ (2012) Systematic meta-analysis of insula volume in schizophrenia. Biol Psychiatry 72:775-784. CrossRef Medline

Sinkkonen J, Tervaniemi M (2000) Towards optimal recording and analysis of the mismatch negativity. Audiol Neurootol 5:235-246. CrossRef Medline

Smieskova R, Fusar-Poli P, Aston J, Simon A, Bendfeldt K, Lenz C, Stieglitz RD, McGuire P, Riecher-Rössler A, Borgwardt SJ (2012) Insular volume abnormalities associated with different transition probabilities to psychosis. Psychol Med 42:1613-1625. CrossRef Medline

Thönnessen H, Boers F, Dammers J, Chen YH, Norra C, Mathiak K (2010) Early sensory encoding of affective prosody: neuromagnetic tomography of emotional category changes. Neuroimage 50:250-259. CrossRef Medline

Tiitinen H, May P, Reinikainen K, Näätänen R (1994) Attentive novelty detection in humans is governed by pre-attentive sensory memory. Nature 372:90-92. CrossRef Medline

Todd J, Michie PT, Jablensky AV (2003) Association between reduced duration mismatch negativity (MMN) and raised temporal discrimination thresholds in schizophrenia. Clin Neurophysiol 114:2061-2070. CrossRef Medline

Tramo MJ, Shah GD, Braida LD (2002) Functional role of auditory cortex in frequency processing and pitch perception. J Neurophysiol 87:122-139. Medline

Umbricht D, Schmid L, Koller R, Vollenweider FX, Hell D, Javitt DC (2000) Ketamine-induced deficits in auditory and visual context-dependent processing in healthy volunteers: implications for models of cognitive deficits in schizophrenia. Arch Gen Psychiatry 57:1139-1147. CrossRef Medline

Whiteside SP (1999) Acoustic characteristics of vocal emotions simulated by actors. Percept Motor Skills 89:1195-1208. CrossRef Medline

Wildgruber D, Ackermann H, Kreifelts B, Ethofer T (2006) Cerebral processing of linguistic and emotional prosody: fMRI studies. Prog Brain Res 156:249-268. CrossRef Medline

Yan CG, Cheung B, Kelly C, Colcombe S, Craddock RC, Di Martino A, Li Q, Zuo XN, Castellanos FX, Milham MP (2013a) A comprehensive assessment of regional variation in the impact of head micromovements on functional connectomics. Neuroimage 76:183-201. CrossRef Medline

Yan FX, Wu CW, Cheng SY, Lim KE, Hsu YY, Liu HL (2013b) Resting-state functional magnetic resonance imaging analysis with seed definition constrained by regional homogeneity. Brain Connect 3:438-449. CrossRef Medline 